\title{
CONTROL PÚBLICO, HACIENDA MUNICIPAL Y MERCADO AGRARIO EN EL REINO DE ARAGÓN DURANTE LOS SIGLOS XVI Y XVII*
}

\author{
Jose ANTONio MATEOS Royo \\ Universidad de Zaragoza
}

RESUMEN: Este artículo analiza la relación entre la evolución de la hacienda municipal y del mercado agrario en Aragón durante los siglos XVI y XVII. La creciente intervención pública en el mercado y la moderación de los ingresos municipales durante el siglo XVI sustentaron el abasto y la demanda, así como intentaron contener la inflación de precios para promover la actividad económica. Sin embargo, el declive económico y demográfico del reino remodeló el mercado agrario durante el siglo XVII. La creciente competencia condujo a una producción agrícola más especializada en algunas áreas y a un funcionamiento más eficiente del mercado. La demanda en ascenso de materias primas desde Francia, Cataluña y Valencia desarrolló la complementariedad del tráfico comercial entre Aragón y regiones vecinas. Por último, esta evolución del mercado modificó la estructura y administración municipal de forma parcial en el Seiscientos. El fuerte endeudamiento municipal impuso una negociación entre elites locales y acreedores $u$ otros grupos sociales para elevar las cargas municipales. En este proceso, las elites urbanas prefirieron una imposición indirecta sobre alimentos básicos, que podía regularse según su comercialización. La oposición de grupos privilegiados y bumildes modificó en ocasiones esta presión fiscal y el control municipal del mercado.

Palabras Clave: Mercado agrario. Hacienda municipal. Aragón. Siglos XVI y XVII.

ABSTRACT: This paper studies the connected evolution of municipal finances and the agrarian market in Aragon during the sixteenth and seventeenth centuries. Increasing public

* Este trabajo se incluye en el proyecto HUM2004-00537, titulado «Absolutismo y mercado. La política del Estado, siglos XVII-XVIII» y financiado por el Ministerio de Ciencia y Tecnología.

Abreviaturas archivísticas: Biblioteca Universitaria de Zaragoza (BUZ), Archivo de la Corona de Aragón, (ACA), Consejo de Aragón, (CA), Archivo Histórico Provincial de Zaragoza (AHPZ), Archivo municipal de Zaragoza (AMZ), Archivo municipal de Albarracín (AMA), Actas municipales (Act. Mun.). 
intervention in the market and the drop in municipal incomes influenced the supply and demand of food, as well trying to halt price inflation in order to promote economic activity. However, economic and demographic decline in the kingdom reorganized the agrarian market during the seventeenth century. Growing competition led to consolidated farming which specialized production in certain areas and led to a more efficient operation of the market. Expanding demand for raw materials coming from France, Catalonia and Valencia belp to develop complementary transactions between Aragon and neighboring regions. Finally, this evolution in the agrarian market partially modified the framework and administration of municipal finances. Raising municipal indebtedness led to a negotiation between local elites and creditors and others social groups in order to increase municipal taxation. In this process, urban elites preferred a indirect way of taxing through foodstuff which could be accommodated according to the degree of commercialization of these raw materials. Opposition coming from privileged groups as well as commoners could sometimes modify both fiscal pressure and municipal control of the market.

KEY WORDS: Agrarian market. Municipal finances. Aragon. Sixteenth and seventeenth centuries.

\section{INTRODUCCIÓN.}

Con toda seguridad, no resulta casual que el estudio de temas tan importantes para entender la Historia Económica preindustrial de España como son la gestión de la hacienda municipal y el control público sobre el mercado durante el Antiguo Régimen experimenten idéntico estancamiento en la actualidad al sufrir una evolución parecida dentro la Historiografía española. Tras contar con algunos precedentes de interés y desarrollarse con fuerte influencia de la Escuela de Annales durante los años setenta y ochenta ${ }^{1}$, tanto la menor atención a las investigaciones económicas dentro de la Historia Medieval y Moderna en beneficio de los análisis políticos, sociales y culturales como la masiva concentración de los trabajos de los economistas en períodos posteriores a

1 Bennassar, Bartolomé: Valladolid en el Siglo de Oro. Una ciudad de Castilla y su entorno agrario en el siglo XVI, Valladolid, 1983; GUTIÉRREZ AlONSO, Adriano: Estudio sobre la decadencia de Castilla. La ciudad de Valladolid en el siglo XVII, Valladolid, 1989; CHACón, Francisco: Murcia en la centuria del Quinientos, Murcia, 1979; RINGrose, David R.: Madrid y la economía española, 15601850, Madrid, 1980; GIMÉNEZ LóPEZ, Enrique: Alicante en el siglo XVIII. Economía de una ciudad portuaria en el Antiguo Régimen, Valencia, 1981; CREMADES, Carmen María: Alimentación y consumo en la ciudad de Murcia durante el siglo XVIII (1701-1766), Murcia, 1984; BERNABÉ, David: Hacienda y mercado urbano en la Oribuela foral moderna, Alicante, 1989; BERNARDOS, José Ubaldo: Trigo castellano y abasto madrileño. Los arrieros y comerciantes segovianos en la Edad Moderna, Salamanca, 2003 y MARTínez RuIz, José Ignacio: Finanzas municipales y crédito público en la España Moderna. La hacienda de la ciudad de Sevilla, 1528-1768, Sevilla, 1992 y «El mercado internacional de cereales y harina y el abastecimiento de la periferia española en el siglo XVIII: Cádiz, entre la regulación y el mercado», en Investigaciones de Historia Económica, (Madrid), 1, (2005), pp. 45-79. 
1850 han provocado en los últimos quince años ${ }^{2}$ que ambas áreas de estudio hayan sido sometidas a un tratamiento tan escaso y aislado por parte de los investigadores que ha impedido completar lagunas, ampliar perspectivas y abordar análisis más amplios.

Dada la reconocida importancia de estos temas para explicar serios cambios estructurales ligados al tránsito de una economía feudal a otra capitalista, su abandono incorporaba a las tendencias de la Historiografía motivaciones de orden práctico. La obligada elaboración de estudios locales, cuyo valor general podía ser discutido, la poca constancia y precisión de las fuentes y la falta de una metodología de trabajo que permitiera homogeneizar resultados, contrastar hipótesis y elaborar sólidas síntesis ${ }^{3}$ desincentivó estas investigaciones o restringió su ámbito temporal en detrimento de una valoración ajustada en el largo plazo de las cuestiones tratadas. Como evidencian los estudios sobre el suministro de grano ${ }^{4}$, los períodos donde una documentación accesible indicaba una expansión del control público sobre el mercado en la España del Antiguo Régimen recibieron un tratamiento privilegiado frente a aquellos como el Seiscientos que requerían una reflexión más compleja para explicar la profunda remodelación del mercado agrario y la intervención pública. Aplicados sobre todo a grandes ciudades, con una mejor representación de los enclaves portuarios sobre los núcleos del interior, los análisis de la política municipal sobre abastos esenciales carecieron de continuidad y perspectiva. Obstáculo añadido, la insuficiente vinculación de los procesos económicos con transformaciones políticas, sociales y culturales ocurridas en el ámbito local durante este amplio período restó profundidad y nitidez a las investigaciones.

Resultado de esta desatención, tanto la gestión municipal como su control sobre el mercado durante el Antiguo Régimen han carecido de valoraciones precisas en beneficio del recurso al tópico. Así lo demuestra la caracterización de la administración municipal como corrupta e ineficaz, con frecuencia sin aportar las pruebas suficientes. En buena parte debido al escaso estudio de la gestión municipal, la distinta incidencia del control público sobre el mercado de productos agrarios durante el Antiguo Régimen ha permanecido ignorada, así como sus repercusiones en la evolución de sus precios ${ }^{5}$. Estas deficiencias

2 Fernández Clemente, Eloy: «La historia económica de España en los últimos veinte años (1975-1995). Crónica de una escisión anunciada», en Jerónimo Zurita, (Zaragoza), 71, (1997), pp. 59-94.

3 Todos estos problemas metodológicos se evidencian en la síntesis sobre las haciendas municipales castellanas elaborada por GUTIÉRREZ ALONSO, Adriano: «Ciudades y monarquía. Las finanzas de los municipios castellanos en los siglos XVI y XVII», en RIBOT, Luis A. y DE ROSA, Luigi (eds.): Ciudad y mundo urbano en la Época Moderna, Madrid, 1997, pp. 187-211.

4 Véase la nota 1 y CASTRO, Concepción de: El pan de Madrid. El abasto de las ciudades españolas del Antiguo Régimen, Madrid, 1987, pp. 47-113.

5 Por este motivo, se carece de síntesis sobre la gestión de la política de abastos durante el Antiguo Régimen y sus repercusiones en los mercados locales y regionales de los principales productos agrarios. 
han consolidado una visión estática de la intervención municipal y el mercado preindustrial que ocluye serios cambios estructurales del sector agrario en la Edad Moderna y sus nexos con los acaecidos en Época Contemporánea. El deseo de incardinar el legado del Antiguo Régimen en debates sobre la evolución económica de España aplicados a los siglos XIX y XX coopera a esta apreciación ${ }^{6}$. Descritas por una documentación más ordenada y precisa, los historiadores resaltan las transformaciones de su etapa final para enlazar con los procesos acaecidos en la Época Contemporánea al tiempo que evitan explorar sus posibles pero menos evidentes nexos con evoluciones ocurridas en etapas anteriores que muy rara vez son contempladas por los economistas.

De acuerdo con estas consideraciones, el presente trabajo reinterpreta los nexos entre hacienda municipal y mercado agrario aragonés durante la época foral moderna a la vez que analiza su incidencia en el tránsito de un modelo económico «autocentrado» a otro «extrovertido» seguida en este territorio ${ }^{7}$. Así, tras afianzarse en el Cuatrocientos, la vertebración de la economía aragonesa se consolidó durante el siglo XVI al crecer la demanda interna, expandirse la superficie roturada y acumularse el capital mercantil. Con todo, el carácter extensivo del crecimiento agrícola favoreció el agotamiento de este modelo «autocentrado» a fines del Quinientos, crisis precipitada por la expulsión de los moriscos en 1610. Los efectos del descenso de la demanda interna derivada de la recesión demográfica fueron agravados por la extinción del capital mercantil aragonés desde fines del siglo XVI y el declive artesanal del Seiscientos, muy pronunciado en la segunda mitad de la centuria y no compensado por el desarrollo de actividades proto-industriales en el medio rural. La irrupción de capital y manufacturas francesas, más competitivas, generó un déficit comercial constante, sancionó el fracaso de la opción industrial e incrementó la demanda foránea de materias primas en el reino. Asentada en ventajas comparativas, pero con serias limitaciones técnicas, una especialización agropecuaria cada vez más orientada hacia la exportación se consolidó en Aragón al afianzarse la producción manufacturera y el desarrollo mercantil en Cataluña a fines del Seiscientos para generarse así un proceso de vinculación entre ambos espacios económicos que continuó en el siglo XVIII y durante toda la Edad Contemporánea.

Enmarcadas en este proceso, el presente artículo aporta dos ideas principales. En primer lugar, defiende el establecimiento una notable especialización y eficiencia del mercado agrario aragonés en el Seiscientos, asumiendo así tanto debates sobre la formación de mercados regionales en Europa durante la Edad Moderna $^{8}$ como sobre la incidencia de la crisis del siglo XVII en la estructura

6 LlOPIS, Enrique (ed.): El legado económico del Antiguo Régimen en España, Barcelona, 2004.

7 Sobre este proceso, TORRAS, Jaume: «La economía aragonesa en la transición al capitalismo. Un ensayo», en Tres estudios de Historia económica de Aragón, Zaragoza, 1982, pp. 9-32

8 Una revisión de las líneas esenciales de este debate en Europa, LLOPIS, Enrique y Jérez, Miguel: «El mercado de trigo en Castilla y León, 1691-1788: arbitraje espacial e intervención», en Historia Agraria, (Murcia), 25, (2001), pp. 15-18. La mayor integración de los mercados regionales 
agraria de la España interior ${ }^{9}$. Favorecida por el mayor volumen y complementariedad del tráfico interregional, esta reestructuración parece iniciar una lenta integración del mercado aragonés durante el Seiscientos que cobra especial nitidez en el comercio de trigo y se consolida al crecer la demanda interna y externa de materias primas en el siglo XVIII. En segundo término, este trabajo explora la incidencia de la intervención municipal sobre ambos modelos económicos. Si el auge económico permitió a los concejos en el Quinientos colaborar en la consolidación de un mercado agrario «autocentrado» al sustentar la demanda interna, la reestructuración del mercado en el Seiscientos remodeló en parte la gestión y composición de las ahora débiles haciendas municipales. El amplio espectro temporal abarcado permite relacionar los cambios económicos con la estrategia de las elites locales, su negociación con otros grupos sociales, gestión de la hacienda municipal y control del mercado. El ámbito espacial, dictado por peculiaridades institucionales, no sólo ayuda a reflejar mejor la compleja relación entre estas variables, sino a vincular cambios estructurales acaecidos en el Antiguo Régimen con el proceso de divergencia económica entre las regiones españolas que culminará en la Época Contemporánea.

\section{El SIGLO XVI. HACIENDA MUNICIPAL Y EXPANSIÓN AGRARIA.}

De forma fehaciente, la expansión económica y demográfica vivida por el Aragón del Quinientos favoreció notables cambios estructurales del sector agrario. La creciente demanda de productos agrícolas ligada al crecimiento poblacional y urbano, la mejora de las comunicaciones, el aumento de las transacciones comerciales y la mayor estabilidad monetaria estimularon no sólo nuevas roturaciones en búsqueda de un crecimiento extensivo de la producción, sino el incremento y mejora de los regadíos en un claro afán por aumentar la produc-

\footnotetext{
y nacionales en Europa durante el siglo XVIII se defiende en PERRSON, Karl Gunnar: Grain markets in Europe, 1500-1900, Cambridge, 1999, pp. 91-130. Para España, GARRABOU, Ramón: «Sobre la formació del mercat catalá en el segle XVIII. Una primera aproximació a base dels preus dels grans á Tarrega (1732-1811)», en Recerques, (Barcelona), 1, (1970), pp. 109-111; EsCRIVÁ, José Luis y LLOPIS, Enrique: «La integración del mercado triguero en la Castilla la Vieja-León del Antiguo régimen: avance y estancamiento», en Hacienda Pública Española, (Madrid), 108-109, (1987), pp. 124-128; LLOPIS, Enrique y JÉREZ, Miguel: «El mercado...», pp. 58-60 y LlOPIS, Enrique (ed.): El legado... pp. 35-38. Los estudios de Llopis sobre el mercado castellano-leonés de trigo defienden la consecución de una mayor eficiencia ya durante la segunda mitad del siglo XVII que iniciaría así este proceso hacia su paulatina integración, desarrollado con mayor nitidez a escala regional y nacional durante el siglo XVIII.

9 ANES, Gonzalo: «La Depresión agraria del siglo XVII en Castilla», en Homenaje a Julio Caro Baroja, Madrid, 1978, pp. 83-100; LLOPIS, Enrique: «El agro castellano en el siglo XVII: ¿Depresión o «reajustes y readaptaciones», en Revista de Historia Económica, (Madrid), V, 1, (1986) pp. 11-37 y Marcos Martín, Alberto: España en los siglos XVI, XVII y XVIII. Economía y Sociedad, Barcelona, 2000, pp. 474-512.
} 
tividad $^{10}$. Como resultado, el análisis de series decimales y múltiples noticias avalan el aumento generalizado de la producción de cereales durante la centuria, la expansión de la vid en muchas poblaciones y el aumento del olivar en zonas de especial aptitud tales como Zaragoza y el Bajo Aragón ${ }^{11}$. Según revelan los estudios realizados sobre la Casa de Ganaderos de Zaragoza ${ }^{12}$, el aumento de los usos pecuarios se tradujo en una notable expansión de la cabaña ganadera.

Las propias instituciones públicas impulsaron estas transformaciones agrarias. El incremento y mejora de los regadíos y sistemas de abasto de agua potable contó con la participación municipal ${ }^{13}$. Distintos organismos promovieron las transacciones desde mediados de siglo, con especial énfasis en el cereal ${ }^{14}$. La Diputación financió con sus ingresos aduaneros reformas municipales de la red de puentes y caminos, sobre todo de aquellos que formaban hacia Francia la principal vía comercial del reino. Las Cortes dispusieron en 1553 la conversión de los sistemas locales de pesos y medidas al de Zaragoza, patrón oficial aragonés. La creciente intervención municipal sobre el mercado de grano se evidencia en la mayor actividad de las panaderías, constituidas en bienes de propios, y en la edificación o compra de molinos por muchos concejos entre mediados del siglo XVI y principios del XVII para controlar el proceso de molturación.

Junto a la regulación del mercado local, la administración municipal influía sobre la producción agraria ${ }^{15}$ mediante intervenciones en el mercado condicio-

10 SALAS, José Antonio: «La evolución demográfica aragonesa en los siglos XVI y XVII», en NadAL, Jordi (ed.): La evolución demográfica bajo los Austrias, Alicante, 1991, pp. 169-179; ColAS, Gregorio: «Las transformaciones de la superficie agraria aragonesa en el siglo XVI: los regadíos. Aproximación a su estudio», en Congreso de historia rural (siglos XV-XIX), Madrid, 1984, pp. 523534; GómeZ ZorRaQuino, José Ignacio: La burguesía mercantil en el Aragón de los siglos XVI y XVII, Zaragoza, 1987 y REDONDO, Guillermo: «Numismática aragonesa en la Edad Moderna», en La moneda aragonesa, Zaragoza, 1983, pp. 209-210.

11 LATORRe, José Manuel: «La producción agraria en el obispado de Huesca (siglos XVIXVII)», en Jerónimo Zurita, (Zaragoza), 59-60, (1991), pp. 131-132, 145; DiARTE, Pascual: La Comunidad de Daroca. Plenitud y crisis (1500-1837), Daroca, 1993, pp. 143-144; MAteOS, José Antonio: Auge y decadencia de un municipio aragonés: el concejo de Daroca en los siglos XVI y XVII, Daroca, 1997, p. 342 y PEIRó, Antonio: Especialización olivarera y crecimiento económico. Caspe en el siglo XVIII, Caspe, 2000, pp. 14-26.

12 La cabaña ligada a la Casa de Ganaderos creció un 80\%, desde 68.000 hasta 122.000 cabezas, entre 1516 y 1599. Véase GrACIA, Daniel: La ganadería zaragozana durante el siglo XVI: la cofradía de San Simón o San Judas o Casa de Ganaderos de Zaragoza, Zaragoza, 1998, memoria de licenciatura inédita.

13 Colas, Gregorio: «Las transformaciones...»y Mateos, José Antonio: «The making of a new landscape: town councils and water in the kingdom of Aragon during the sixteenth century», en Rural History, (Cambridge), 9, 2, (1998) pp. 123-139.

14 COLAS, Gregorio y SALAS, José Antonio: Aragón en el siglo XVI. Alteraciones sociales y conflictos políticos, Zaragoza, 1982, pp. 42-46; SALAS, José Antonio: La población de Barbastro en los siglos XVI y XVII, Zaragoza, 1981, pp. 105-106; MATEOS, José Antonio: Auge... pp. 268-269, 388-389.

15 SALAS, José Antonio: «Las haciendas concejiles aragonesas en los siglos XVI y XVII. De la euforia a la quiebra», en Poder político e instituciones en la España Moderna, Alicante, 1992, pp. 11-66 
nadas por la estructura de la hacienda y concepto de la gestión. El limitado peso demográfico de los concejos y la herencia de la Baja Edad Media impuso a las haciendas municipales una simplicidad que sólo se abandonó de forma paulatina durante el Quinientos. Muestra de este legado, la asunción de nuevos cometidos provocó la creación de administraciones subsidiarias de la caja central, vinculadas con frecuencia a la política de abastos. Esta estructura limitó el aumento de ingresos y gastos hasta el punto de que estos últimos sólo se expandieron con fuerza en la segunda mitad de la centuria gracias al endeudamiento censal tras crecer la oferta de crédito por parte de las elites rectoras.

La composición de los ingresos municipales refleja múltiples variantes. Así, la importancia de los cequiajes o alfardas y el arriendo de pastos osciló mucho entre los municipios según la extensión de sus regadíos y alfoces. Con todo, los monopolios y corretajes sobre la venta al por menor de alimentos básicos - carne, tocino, pescado, pan, vino, aceite- constituyeron el núcleo esencial de la caja central durante el siglo XVI ${ }^{16}$. Resultado probable de la existencia de aduanas fronterizas regidas por la Diputación, los corretajes sobre las restantes mercancías, peajes y pontazgos no generaron rendimientos considerables. Los ingresos derivados de tierras, casas u otros inmuebles propiedad del concejo se estancaron durante el Quinientos al cederse por un canon fijo modesto que también rigió la entrega a particulares del usufructo sobre ciertas tierras comunales. El cobro de multas o derechos judiciales reportó sumas muy escasas.

Sobre esta estructura, como revela la evolución de los ingresos del concejo de Daroca en 1518-1672 expuesta en el Gráfico 1, la presión fiscal municipal sobre los principales productos agrarios permaneció baja en Aragón durante toda la centuria. Cierta inercia en la gestión respecto a su concepción medieval impidió actualizar los ingresos derivados de impuestos o introducir otros nuevos sobre productos cuyo cultivo crecía, como el vino. La recaudación de sisas o impuestos extraordinarios - fijados por lo común sobre el trigo y la carne- sin su sanción previa en Cortes quedaba prohibida desde 1398 por el fuero «De probibitione sisarum»17. Al disminuir estas convocatorias bajo el reinado de Felipe II, se privó a los concejos de realengo y señores laicos o eclesiásticos de su aplicación por tres años

\footnotetext{
y MAteos, José Antonio: «Propios, arbitrios y comunales: la hacienda municipal en el reino de Aragón durante los siglos XVI y XVII», en Revista de Historia Económica, (Madrid), XXI, 1, (2003), pp. 51-77. Para su comparación con los ingresos municipales en las Coronas de Aragón y Castilla durante los siglos XVI y XVII, véase Fiscalitat estatal i hisenda local (ss.XVI-XIX): funcionament i repercussions socials, Palma de Mallorca, 1998; GutiérReZ ALONSO, Adriano: «Ciudades y monarquía...» pp. 189-199 y BERNABÉ, David: «La fiscalidad de los territorios peninsulares de la Corona de Aragón durante la época de los Austrias», en FORTEA, José Ignacio y CREMADES, Carmen María (eds.): Política y bacienda en el Antiguo Régimen, Murcia, 1993, pp. 15-31.

16 Véase la nota anterior.

17 Monsoriu, Bernardino de: Summa de todos los fueros y observancias del reyno de Aragón y determinaciones de micer Miguel del Molino, Zaragoza, 1982, facsímil del original impreso en Zaragoza en 1589, fol. 156r-157r. Sobre el tema, MATEOS, José Antonio: «Propios, arbitrios...», p. 57.
} 
tras recaudar por otros tres las sisas para sufragar los servicios al monarca votados en Cortes. Por último, condicionados por su interés en proteger al consumidor y potenciar la actividad económica, los municipios moderaron los ingresos procedentes de corretajes y monopolios sobre alimentos básicos para contener el alza de precios y sustentar la demanda de la población. Así, los ingresos de los monopolios sobre la carne, el tocino o el pescado cuyo consumo iba en constante ascenso gracias al crecimiento demográfico se estabilizaron al centrarse las pujas para su consecución en rebajas del precio de venta ofrecido al público ${ }^{18}$.

\section{GRÁFICO 1. EVOLUCION DE LOS INGRESOS DE LA HACIENDA MUNICIPAL DE DAROCA (1518-1672) —EN SUELDOS-}

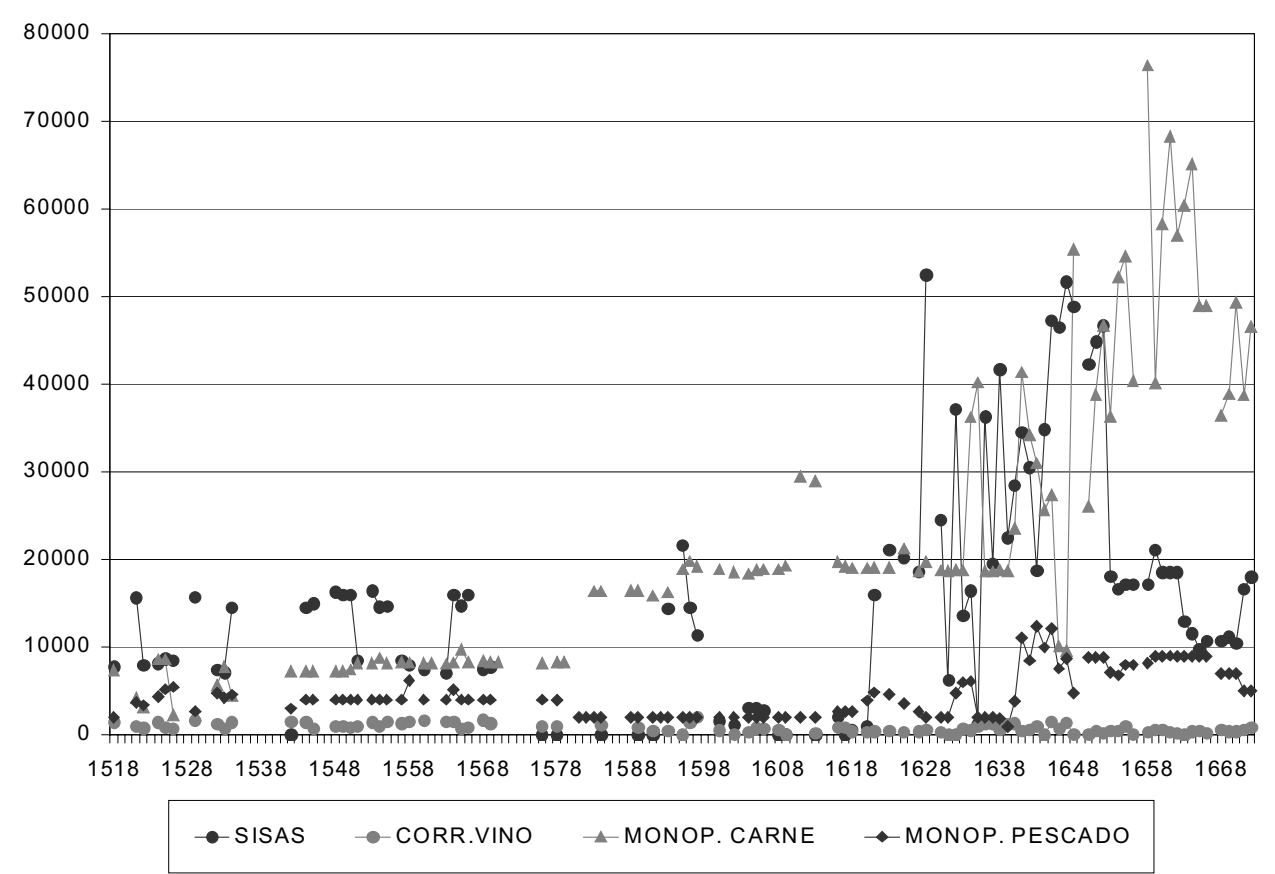

Fuentes: MATEOS, José Antonio: Auge... pp. 461-462, 467-468. Nota: Corr. $=$ corretaje, monop. $=$ monopolio.

Esta restricción de los ingresos moderó el ascenso de los precios ante el fuerte aumento de la demanda, sobre todo en la segunda mitad del siglo.

18 Mateos, José Antonio: Auge... pp. 461-462, 467 y «Municipio y mercado en el Aragón moderno: el abasto de carne en Zaragoza (siglos XVI y XVII)», en Espacio, Tiempo y Forma, (Madrid), IV, 16, (2003), p. 189. 
Arrendados los monopolios esenciales por ciudadanos e infanzones ${ }^{19}$, si bien sus vínculos con la oligarquía municipal pudieron ganarles ocasionales tratos de favor, la presencia de representantes de artesanos y labradores en las pujas limitó estas actuaciones. Incluso un monopolio susceptible de generar elevados ingresos en Zaragoza como el fijado sobre la carne, pese a ofrecerse en el Quinientos por sumas muy modestas, sólo fue arrendado en ocasiones por los grandes comerciantes de la capital. Resultado de este sacrificio financiero, el precio de la carne ascendió en Zaragoza con mayor lentitud que en otras ciudades aragonesas durante los dos primeros tercios de siglo para superarlas levemente el resto de la centuria. Al verse obligados los concejos por su endeudamiento a aumentar los ingresos de los principales abastos a fines del siglo XVI y principios del XVII, tuvieron que asumir con frecuencia su gestión tras cesar las pujas por su arriendo al estimarse excesivo el riesgo de contraer pérdidas debido a la inflación de precios.

Esta gestión municipal se ve corroboraba por la creación de administraciones subsidiarias ligadas a la política de abastos. La institución emblemática es la cámara del trigo o pósito, adoptada en muchas ciudades, villas y lugares ${ }^{20}$. Receptores de un interés por la protección al consumidor latente en la política económica medieval ${ }^{21}$, algunos pósitos surgieron tras padecerse serias carestías de grano que legitimaron su fundación. Las elites rectoras añadieron su interés como productores o distribuidores de grano por expandir el mercado público local de cereal y sustentar la demanda interna, proceso muy difícil en las economías preindustriales ${ }^{22}$. Así se explica la extensión de los pósitos a núcleos agrarios en zonas cerealistas, con menor necesidad de un abasto regular de trigo que las grandes ciudades. Al desarrollar mecanismos de contención frente a la inflación de precios, que incidía con mayor fuerza en los productos agrarios, se favorecía el consumo de grano y la capacidad adquisitiva de la población. A cambio de ver rebajado el precio de mercado, el productor obtenía una mayor regularidad de la demanda de grano. Se conseguía así incentivar el cultivo de cereal al procurar una integración voluntaria del campesino en el mercado ${ }^{23}$.

19 Véase la nota anterior, SALAS, José Antonio: La población... pp. 94-95; OTERO, Félix: La Vila de Fraga al segle XVII, vol.1, Calaceite, 1994, p. 148; MATEOS, José Antonio: Auge... pp. 315318, 326-330 y URZAY, J. Ángel, SANGÜESA, Antonio, e IBARRA, Isabel: Calatayud a finales del siglo XVI y principios del XVII (1570-1610), Calatayud, 2001, pp. 142-143.

20 MATEOS, José Antonio: «Control público, mercado y sociedad preindustrial; las cámaras de trigo en el reino de Aragón durante los siglos XVI y XVII», en Historia Agraria, (Murcia), 34, (2004), pp. 15-18.

21 Postan, M.M, Rich, E.E. y Miller, Edward: Organización y Política Económica en la Edad Media, Madrid, 1972: Historia económica de Europa, vol.3, pp. 507-547.

22 Sobre el tema, VRIES, Jean de: La economía de Europa en un período de crisis, 1600-1750, Madrid, 1987, $3^{\mathrm{a}}$ ed., pp. 181-186.

23 AYMARD, Maurice: "Autoconsommation et marchés: Chayanov, Labrousse ou Le Roy Ladurie?», en Annales, Economies, Societés, Civilisations, (Paris), 38/6, (1983), pp. 1392-1410. El consenso social en torno al mercado público de grano que entraña la formación de pósitos en 
Bien por problemas económicos o disensiones políticas y sociales, este sistema no se consolidó por igual en todas las poblaciones: cuanto más abundante y regular era el abasto del pósito, mayor confianza y dinamismo generaba en un mercado en expansión. Al constituir el trigo un artículo indispensable, los efectos de esta intervención excedieron los límites del comercio local o comarcal de grano y afectaron al conjunto de la economía aragonesa.

Esta intervención municipal sobre el mercado ganó peso durante el Quinientos conforme los pósitos aumentaron sus existencias y vendieron más trigo a la población ${ }^{24}$. Al situar el precio de venta muy cercano al de mercado en años normales para sustentar la demanda y rebajarlo asumiendo pérdidas ante carestías para combatir la especulación y paliar la escasez, la subsistencia financiera de los pósitos dependió de las oscilaciones de precios del trigo. El análisis de su evolución durante los siglos XVI y XVII en Aragón, expuesta en el gráfico 2 y el cuadro 4, demuestra que este sistema de abastos fue sostenido en las décadas centrales del Quinientos por el espaciamiento de los años de escasez y una estable progresión de los precios a cuyo mantenimiento cooperaba la actuación de los pósitos sobre el mercado de grano ${ }^{25}$. Generadas de forma probable por rendimientos decrecientes en las cosechas, serias carestías en las tres últimas décadas del siglo provocaron oscilaciones muy bruscas de precios en el mercado. Las cuantiosas existencias de grano debían venderse a un precio muy inferior al de su adquisición y se produjeron serias pérdidas. Pese al recurso al crédito, esta gestión resultó demasiado gravosa y se impuso una administración más rentable en el siglo XVII.

La extensión al vino y al aceite de la política de abastos aplicada al grano resultó más problemática. En primer lugar, muchos concejos no incluían monopolios de venta sobre estos productos entre sus bienes de propios, lo que dificultaba una mayor intervención. En segundo término, la regulación de su venta en el mercado incorporaba una protección al productor más arraigada que en el trigo o la carne. Por ambas causas, la fundación de organismos dedicados a la contención de precios aglutinó un menor consenso social y fue tardía y difícil. Solía afectar a áreas carentes de estos cultivos por razones climáticas o donde los intereses del productor no se afianzaron. La reticencia concejil a aumentar la presión fiscal y la menor percepción vecinal de su necesidad limitó su instauración, en especial si se expandía la vid y el olivo en las inmediaciones o el aumento del

\footnotetext{
Aragón durante el siglo XVI refleja los campos de intereses comunes entre grupos sociales y sus expectativas de mejores resultados al cerrarse acuerdo descritos por GAUTHIER, David: La moral por acuerdo, Barcelona, 1994 y POLANYI, Karl: La gran transformación. Los orígenes políticos y económicos de nuestro tiempo, México, 1992.

24 Mateos, José Antonio: «Control público...» pp. 18-22.

25 Con distinto énfasis incluso en los productos alimenticios básicos, la política municipal de abastos contribuiría a explicar en ciertos territorios la moderada revolución de los precios españoles entre 1550 y 1625 expuesta en MARTín ACEÑA, Pablo: «Los precios en Europa durante los siglos XVI y XVII: estudio comparativo», en Revista de Historia Económica, (Madrid), X, 3, (1992), pp. 368-370.
} 
gasto municipal en la segunda mitad de siglo hallaba otros campos prioritarios de aplicación, como las Obras Públicas, los regadíos o el ceremonial.

Gráfico 2. Evolucion del precio del trigo en Zaragoza, Daroca, BarBASTRO Y FRAGA (1500-1707) —EN SUELDOS POR CAHÍZ-

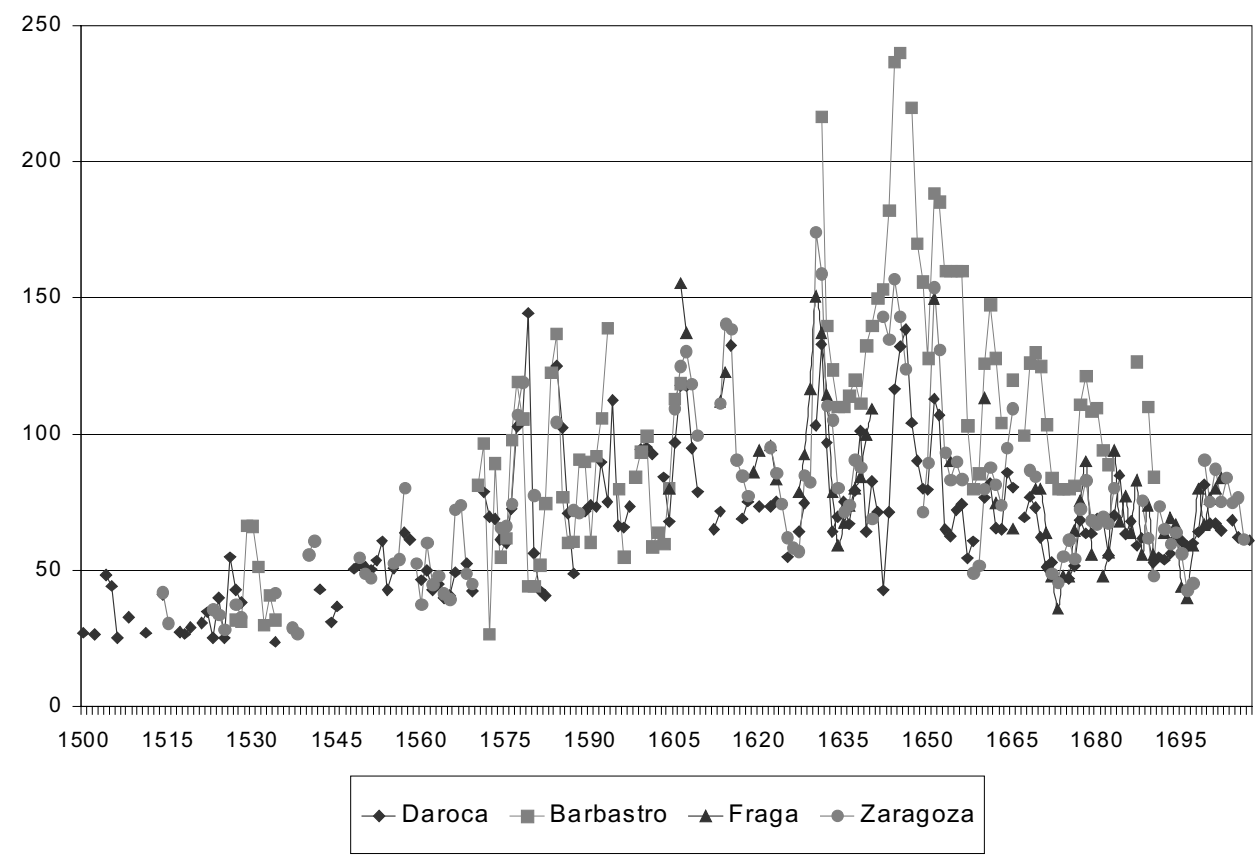

Fuentes: Para Barbastro, SALAS, José Antonio: La población... pp.101, 348 y «La incidencia social y coste económico de la peste de 1531 en Barbastro", en Estudios, 80, (1983), pp.36-37. Sobre Daroca, Mateos, José Antonio: Auge... pp. 494-497. Para Fraga, Berenguer, Antonio: «Un ejemplo para el estudio de los libros de cofradías de oficios: la cofradía de San Joseph de Fraga», en $A r$ gensola, (Huesca), 107, (1993), p.245 y OTERO, Félix: La Vila... vol. 1, p. 144. Sobre Zaragoza, AMZ, Act. Mun, 1513-1697, Bastardelos, 1550-1706, Libros de contratos de la ciudad, (795) y contabilidad del Pósito y de las panaderías en Cajas 479, 480, 481, 482, 492, 495, 7765 y 7887 (elaboración propia). Nota: el cahíz aragonés equivale a 140 kilogramos ó 179,36 litros.

Consolidada gracias a la fuerte expansión de la vid durante el siglo XVI, la protección al productor condicionó la regulación pública del abasto de vino ${ }^{26}$. Como ya sucedía en la Baja Edad Media, la legislación municipal reservaba el

26 SAn ViCente, Ángel: Colección de fuentes de derecho municipal del Bajo Renacimiento, Zaragoza, 1970, pp. 79-80, 472-473; SALAS, José Antonio: La población... pp. 108-116; MATEOS, José Antonio: Auge... pp. 339-351 y BUZ, sign. D-21-75, fol.30-53. 
mercado local para los excedentes de los vecinos y creaba áreas preferentes de producción y consumo entre las ciudades y los lugares de su entorno. Si bien muchos concejos contaban con un monopolio de venta de vino - la taberna-, con capacidad de abastecerse en el exterior, su incidencia era limitada. La reducción de la competencia en el mercado local aumentaba los precios y favorecía la venta ilegal de vinos forasteros más baratos, cuya introducción intentaron frenar las normas municipales en la segunda mitad de siglo. Si el núcleo carecía de vino o su precio se elevaba en exceso, el concejo permitía entrar vino forastero o asumía su compra para venderlo a la población. Prueba de las limitaciones de este monopolio ante las carencias del sur aragonés, las Comunidades de Teruel y Albarracín obtuvieron el privilegio de importar vino de Valencia libre de tasas aduaneras, mantenido tras suprimirse sus leyes privativas en 1598 hasta la derogación del sistema foral aragonés ${ }^{27}$. Caso de existir, los monopolios y corretajes sobre el vino reportaron modestos ingresos para paliar el ascenso de los precios. El uso de distintas medidas de capacidad entre las poblaciones y las limitadas series de precios del vino disponibles impiden ponderar su evolución en Aragón durante la centuria. Con todo, las dificultades de abasto vividas en Zaragoza, Daroca y Barbastro a fines del siglo XVI y principios del siglo XVII evidencian un creciente consumo durante la segunda mitad del Quinientos que aumentó su valor en el mercado y el recurso al vino forastero ${ }^{28}$. La mayor demanda e insuficiencia de la producción propia impuso en la capital desde mediados del siglo XVI un ascenso más temprano de su precio.

Más matizada por la menor extensión de su cultivo en el reino, la protección al productor condicionaba la regulación del mercado del aceite ${ }^{29}$. En municipios con excedentes, su oferta por los vecinos se impuso sin mediar monopolio de venta o ni siquiera corretajes específicos, como sucedía en Zaragoza. Si bien muchos concejos contaban con este monopolio de venta, los núcleos incapaces de abastecerse de aceite dependían de mercaderes que vendían al por mayor esta mercancía, susceptible de conservarse almacenada varios años. Menos frecuentes y más tardías que los pósitos, las cámaras de aceite surgieron en ciudades como Huesca, Daroca o Calatayud a partir de monopolios incluidos en sus propios ${ }^{30}$. Recogieron idéntico interés por abastecer a la población y con-

27 AMA, doc.1, fol.78-79, doc.67, fol.80r-101v y Archivo de la Diputación Provincial de Zaragoza, Manuscrito 734, fol.432-456.

28 SAlas, José Antonio: La población... p. 114; Mateos, José Antonio: Auge... pp. 342, 500501 y AMZ, Act. Mun., 1549, 16 de octubre, 1574, 6 de noviembre, 1577, 18 de septiembre, 1590, 16 de enero, 1605, 22 de marzo, 1614, 13 de septiembre y Libros de pregones, números 5, 6, $7,8,9,12,13$ y 14 .

29 SAN Vicente, Ángel: Colección... p. 73; SALas, José Antonio: La población... pp. 116-119 y BUZ, sign. D-21-75, fol.54-84.

30 INGLADA, Jesús: Estudio de la estructura socio-económica de Huesca y su comarca en el siglo XVII, Zaragoza, 1987, memoria de licenciatura inédita, p. 60; MATEOS, José Antonio: Auge... pp. 351365 y UrZay, J. Ángel, SANGÜESA, Antonio e IbarRA, Isabel: Calatayud... pp. 144-145. 
tener el alza de precios; pero gestionaron menos dinero y asumieron menos pérdidas que los pósitos en años de escasez. Con todo, su volumen de suministro en Calatayud y Daroca a fines del siglo XVI y principios del XVII resultó notable y propició menores alzas de precios en esta última ciudad frente a Zaragoza —-véase el Gráfico 3-. Si bien su fundación no implicó en algunos núcleos expectativas de aumentar la producción local de aceite por razones climáticas, la reestructuración de la producción agraria del siglo XVII confirmó la expansión de su cultivo en otros —Calatayud, Huesca_- donde su demanda sí había sido sustentada por estas cámaras.

Amén de las dificultades financieras, esta intervención municipal más modesta en el mercado de aceite revela un menor consenso social en la contención de precios. En núcleos con fuertes excedentes de aceite sometidos a una creciente demanda como Zaragoza, influyó la presión de la elite de infanzones y ciudadanos productores. Estos intereses llevaron al concejo en la segunda mitad del Quinientos a triplicar los precios máximos de mercado fijados a principios de siglo que permitían la entrada de aceite forastero — más barato — en detrimento del consumidor local al limitar la competencia ${ }^{31}$. Como resultado, su precio aumentó con constancia en la segunda mitad del Quinientos y sufrió fuertes fluctuaciones a principios del siglo XVII —-véase el Gráfico 3 y cuadro 5- que desajustaron el abasto urbano, pero no alteraron su regulación municipal.

\section{EL SIGLO XVII: LA REESTRUCTURACIÓN DEL MERCADO AGRARIO.}

Las dificultades de los concejos para regular el mercado agrario según la política aplicada en el Quinientos fueron agudizadas no sólo por sus apuros financieros, sino por la decadencia económica y demográfica del reino aragonés durante el siglo XVII. Si ya a fines del siglo XVI se perciben síntomas de estancamiento, la expulsión de los moriscos en 1610 añadió una sangría poblacional y un serio golpe al mecanismo de detracción señorial laico que repercutió en toda la economía y dañó en especial al sistema financiero ${ }^{32}$. El continuo declive de la producción industrial y artesanal, muy marcado en la segunda mitad de la centuria, se vio precipitado por la retracción del capital mercantil aragonés a fines del siglo XVI y principios del XVII 33 . Ejercido el control de las principales transacciones en el reino por comerciantes genoveses en 1580-1620 y

31 BUZ, sign. D-21-75, fol.53-68.

32 SALAS, José Antonio: «La evolución demográfica...», pp. 169-179. Sobre la incidencia de la expulsión de los moriscos en la economía aragonesa, ABADIA, Alejandro: La enajenación de rentas señoriales en el reino de Aragón, Zaragoza, 1998.

33 REDONDO, Guillermo: Las corporaciones de artesanos de Zaragoza en el siglo XVII, Zaragoza, 1982 y PEIRÓ, Antonio: «Comercio de trigo y desindustrialización: las relaciones económicas entre Aragón y Cataluña", en Las relaciones económicas entre Aragón y Cataluña (siglos XVIII-XX), Huesca, 1990, pp. 41-51. 
franceses a partir de esta última fecha, la recuperación de la burguesía mercantil aragonesa en la segunda mitad de la centuria no excluyó la presencia de mercaderes franceses y mostró una orientación más rentista y menos comercial ${ }^{4}$. La existencia de fuertes alteraciones monetarias ante la invasión de piezas forasteras falsas, defectuosas o de menor ley ${ }^{35}$ condicionó los intercambios desde inicios de la centuria y favoreció en ciertos períodos la inflación de los precios de manufacturas y alimentos. La mayor presión fiscal desplegada por la monarquía y las instituciones públicas aragonesas contribuyó a desajustar y remodelar los mercados ${ }^{36}$.

Unido a estos factores, si bien estudios recientes han moderado las pérdidas globales sufridas en el Seiscientos ${ }^{37}$, resulta evidente el estancamiento demográfico de Aragón ante la lenta recuperación vivida tras las fuertes acometidas de la peste bubónica en 1651-54 que sólo se consolidó en sus décadas finales. Perceptible en el claro descenso de su precio - véase los gráficos 2,3 y 5 y los cuadros 4, 5 y 6 - desde mediados de siglo, los cereales y otros productos agrarios sufrieron una contracción en su demanda interna que facilitó la remodelación de la economía del reino, en especial su mayor extroversión durante la segunda mitad de la centuria. Propiciada por la irrupción de capital mercantil extranjero y la creciente demanda de materias primas por otros territorios, tras afianzar sus ventajas comparativas, la producción agropecuaria aragonesa se vio impelida así a una mayor orientación exportadora hacia Francia, Valencia y en especial Cataluña, con un marcado peso de la lana y los cereales ${ }^{38}$.

Junto a este proceso global, agudizada por la misma presión fiscal municipal, la contracción de la demanda interna impulsó una fuerte reestructuración de la producción agraria local y comarcal en Aragón durante el Seiscientos, mayor de la reconocida para el área mediterránea española ${ }^{39}$. Como refleja la evolución de los diezmos percibidos en la villa de Ejea y los obispados de Hues-

34 GÓmeZ ZORRAQUiNO, José Ignacio: La burguesía mercantil... y Zaragoza y el capital comercial. La burguesía mercantil en el Aragón de la segunda mitad del siglo XVII, Zaragoza, 1987. Muestra de su orientación más rentista, la adquisición de tierras a nobles endeudados, la compra y arriendo de inmuebles y los préstamos a la monarquía ganaron terreno entre las actividades de la burguesía mercantil zaragozana en la segunda mitad del siglo XVII.

35 REDONDO, Guillermo: «Numismática aragonesa...» pp. 209-213 y MATEU, Felipe: «El sistema monetario en Aragón. Síntesis histórica», en La moneda aragonesa, Zaragoza, 1983, pp. 123-127.

36 Mateos, José Antonio: «Propios, arbitrios...» pp. 67-68.

37 SALAS, José Antonio: «La población aragonesa a comienzos del siglo XVIII», en FERRER, José Antonio (dir.): El conde de Aranda y su tiempo, vol.1, Zaragoza, 2000, pp. 355-372.

38 REDONDO, Guillermo: «Las relaciones comerciales Aragón-Francia en la Edad Moderna: datos para su estudio en el siglo XVII», en Estudios, (Zaragoza), 85-86, (1985), pp. 123-154; PEIRÓ, Antonio: «Comercio de trigo...» y TORRAS, Jaume: «La economía aragonesa...», pp. 9-32 y «Relaciones económicas entre Aragón y Cataluña antes del ferrocarril», en Las relaciones económicas entre Aragón y Cataluña (siglos XVIII-XX), Huesca, 1990, pp. 17-31.

39 Marcos Martín, Alberto: España... pp. 492-495. 
ca y Teruel durante el Seiscientos ${ }^{40}$, se inició con el descenso de la producción agrícola en Aragón durante la primera mitad de siglo, con especial énfasis en los cereales. Su lenta recuperación durante la segunda mitad de la centuria, ya iniciada en 1660 en Teruel y demorada en Ejea y Huesca hasta sus dos décadas finales, permitió remodelar la producción agraria. La reestructuración incluyó cierto aumento de usos ganaderos estantes en zonas de especial aptitud como el sur aragonés —comarcas de Albarracín, Teruel, Daroca y Alcañiz-, sobre todo en núcleos carentes de producciones agrícolas competitivas o donde éstas no se habían consolidado aún ${ }^{41}$. Este proceso, que ahorraba mano de obra, incluyó la conversión de las tierras cultivadas menos fértiles en pastos, la creación de nuevas dehesas municipales y la fundación de algunas asociaciones de ganaderos, sobre todo desde mediados de siglo ${ }^{42}$. La posibilidad de exportar la lana a los Países Bajos y Francia, máxime ante el serio retroceso de la industria textil autóctona, unida a la de comercializar la carne en Cataluña, Valencia o Zaragoza volvió atractiva la propiedad de reses como actividad complementaria para la burguesía mercantil de la capital aragonesa durante la segunda mitad de la centuria ${ }^{43}$.

La reestructuración de los cultivos agrícolas vino asimismo propiciada por una mayor especialización productiva. Pese a la protección municipal sobre los excedentes locales, este proceso se evidenció en artículos de fácil comercialización como el vino o el aceite. Ya detectada a fines del siglo XVI ó principios del XVII, esta especialización de ciertas áreas creció en la segunda mitad del Seiscientos hasta convertirse sus precios de mercado en referencia en años de carestía para las ciudades próximas, incluida Zaragoza ${ }^{44}$. Así sucede en las comarcas de Cariñena y Calatayud para el vino o en el Bajo Aragón y la comarca

40 LATORRE, José Manuel: «La producción agraria...», pp. 131-146 y «La producción agraria en el sur de Aragón (1660-1827)» (ejemplar mimeografiado) y MORENO ALMARCEGUI, Antonio: «Población y producción agrícola en el Norte aragonés (1598-1820)», en Congreso de historia rural (siglos XV-XIX), Madrid, 1984, p. 490.

41 Una posible reducción de la cabaña ganadera explicaría el aumento de estos usos estantes en el sur aragonés durante el Seiscientos y el descenso de la trashumancia desde Teruel al reino de Valencia durante los dos últimos tercios del siglo XVII defendido en CASTÁN, José Luis: Pastores turolenses. Historia de la trashumancia aragonesa en el reino de Valencia durante la época foral moderna, Zaragoza, 2002, pp. 353-364. Este proceso no debilitó el predominio del trigo — superior a un 70\% - ni la caída de la cebada frente al centeno en los diezmos del cereal cobrados en el obispado de Teruel durante la segunda mitad del siglo XVII. Los cereales inferiores, sobre todo la cebada, están mejor representados en los diezmos percibidos en Huesca y otros lugares anexos durante el Seiscientos. Véase la nota anterior.

42 Mateos, José Antonio: Auge... pp. 423-424; Archivo Municipal de Alcañiz, Protocolos Notariales, José Peralta, 1667, 28 de diciembre, fol.3r-13v y 1673-74, 1 de noviembre de 1673, fol.144v-149v y AMA, doc. 67, fol.44r-46v, doc. 87 y doc.141, Libros de Mayordomía, 1621-1654.

43 Gómez ZorraQuiNo, José Ignacio: Zaragoza... pp. 85-86, 161-162.

44 Para la limitada especialización agrícola desarrollada en el área mediterránea durante el siglo XVII, Marcos MarTín, Alberto: España... pp. 487-491. 
de Calatayud para el aceite 45 . En correspondencia, concejos como Fraga adaptaron su producción agraria a su papel de receptores de ambas mercancías ${ }^{46}$. Este proceso cobró impulso al crecer la demanda interna de estos productos junto con la población aragonesa en el Setecientos, como revelan las frecuentes introducciones fraudulentas de vino forastero en Huesca durante la segunda mitad de la centuria que compensan su mayor dedicación al aceite o la decisión de Ejea a fines de siglo de ampliar sus cultivos de cereal y renunciar a abastecerse con su producción local de vino por no considerarla ya rentable ${ }^{47}$.

Grafico 3. EVOluCiOn DE los PRECIOS DEL ACEITE EN ZARAgOZA y DAROCA (1572-1708) - EN SUELDOS POR ARROBA-

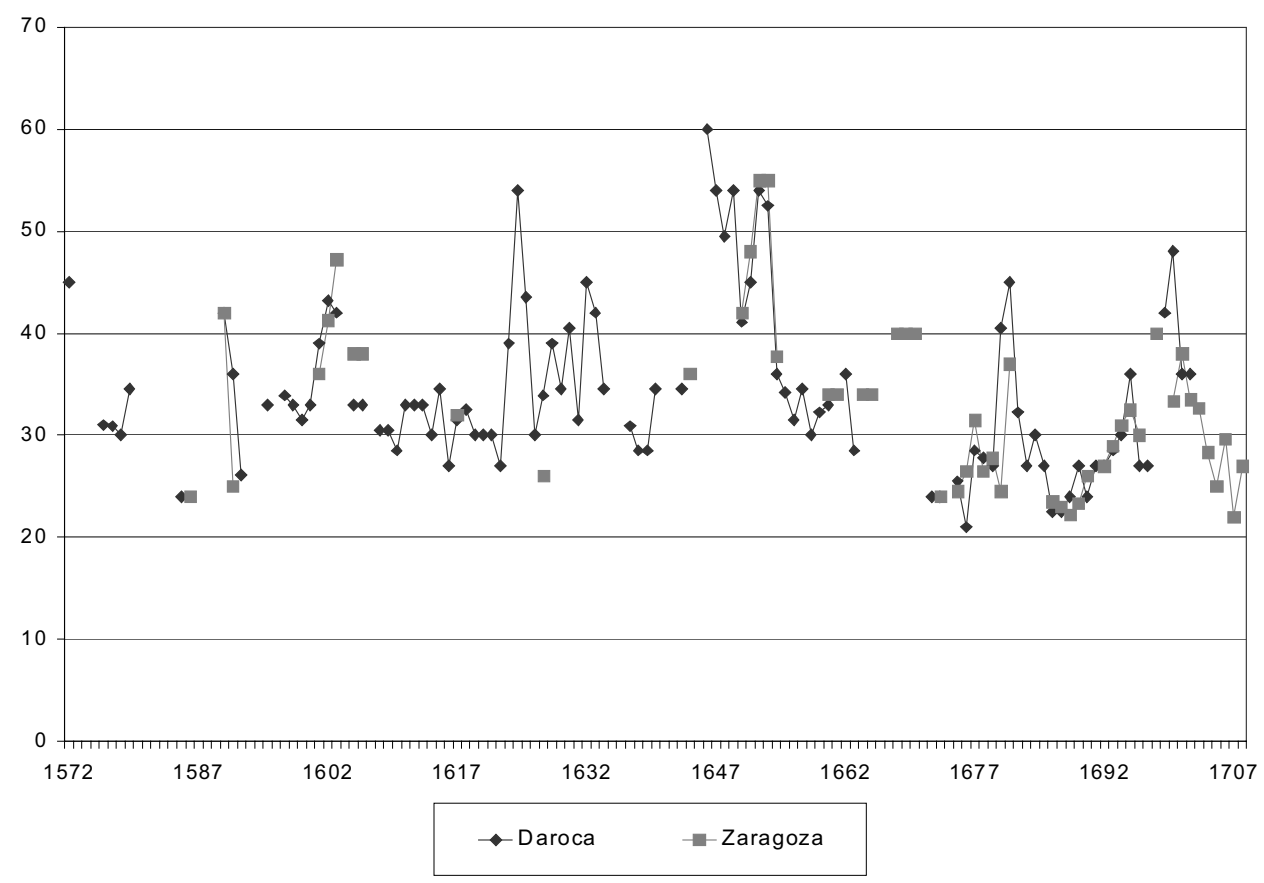

Fuentes: Mateos, José Antonio: Auge... p. 502 y AMZ, Act. Mun., 1590-1707 y Bastardelos, 1650-1706 (elaboración propia). Nota: la arroba de aceite aragonesa equivale a 13,93 litros.

45 La especialización vinícola de la comarca de Cariñena, en AMZ, Act. Mun., 1577, 18 de septiembre, 1614, 13 de septiembre, 1644, 9 de marzo y Caja 14, sign. 2-3-19 y MATEOS, José Antonio: Auge... p. 347. La creciente producción de aceite del Bajo Aragón, en PeIRó, Antonio: Especialización... pp. 14-33. La comercialización de vino y aceite elaborados en la comarca de Calatayud, en ACA, CA, legajos 59, 74, 76 y 77, y MATEOS, José Antonio: Auge... p. 358.

46 Otero, Félix: La Vila... vol.1, pp. 44-45.

47 Moreno Almarcegui, Antonio: «Población y producción...» pp. 493-494. 
Ante el fuerte descenso de la demanda interna en la segunda mitad del siglo XVII, este afianzamiento de la especialización generó una mayor competencia en el mercado regional. Así lo testimonian los mayores esfuerzos municipales para asegurar a los vecinos la salida de sus excedentes de vino en el mercado local, que incluyeron efectuar estimaciones de existencias y futuras cosechas, tasar los precios de venta y rescindir acuerdos preferentes de suministro mutuo firmados con lugares del entorno ${ }^{48}$. Precipitadas por el ascenso arancelario decretado por las Cortes aragonesas de 1677-78, las trabas impuestas en las dos últimas décadas del siglo por Castilla y Navarra a la venta de vino aragonés - junto al aceite y jabón - o al tránsito por sus territorios hacia Bilbao y San Sebastián agudizaron este proceso en comarcas afectadas - Calatayud - al orientar la comercialización de su vino aún más hacia el mercado interior ${ }^{49}$. Resultado de la mayor competencia, tras haber crecido la plantación de vid en Aragón a lo largo del siglo XVI, retrocedió en ciertas zonas durante la segunda mitad del Seiscientos: en Huesca parece sustituirse por olivos ${ }^{50}$. Caso de avanzar su cultivo en otras áreas, fue regulado por los municipios según su comercialización. Al decrecer la población en Zaragoza, sustituir la vid al cereal en tierras de regadío y decaer la calidad de los caldos y su salida al mercado, el concejo rescindió en 1661 a núcleos del entorno la licencia de vender uvas y vino en la ciudad otorgada en 1616 y prohibió nuevas plantaciones en huertas y montes por temor a una caída de los precios del vino y la producción de granosi. Tras constatar la escasa competitividad de sus vinos fuera de Barbastro por su baja calidad y altos precios, el municipio prohibió en 1676 cultivar vid en tierras yermas al tiempo que intentaba detener la tala de olivos en el términos2.

Patente ante carestías locales o años de fuerte demanda de vino en Aragón - como la década de los cuarenta, ante la presencia de la Corte y el ejército castellanos-, la mayor producción de Cariñeña, Longares y Paniza pudo difundirse en el mercado regionals3 durante la segunda mitad del siglo XVII gra-

48 Salas, José Antonio: La población... pp. 109-116; Mateos, José Antonio: Auge... pp. 344-351, OTERo, Félix: La Vila... vol.1, p. 44 y AMZ, Act. Mun., 1644, 30 de enero y Caja 14, sign. 2/3/1.

49 ACA, CA, legajos 59, 74, 75, 76 y 77 y BORRAs, Gonzalo: La guerra de Sucesión en Zaragoza, Zaragoza, 1972, pp. 25-26. Ya en 1682 la monarquía trató de impedir la venta de vino aragonés en Castilla por parte de mercaderes de la Comunidad de Calatayud para frenar la extracción de plata. Las Cortes navarras prohibieron su importación desde 1684-85 y sólo permitieron su tránsito hacia Bilbao ó San Sebastián bajo fuertes impuestos, difíciles de evitar al rechazar el Consejo de Castilla la licencia de tránsito por la Rioja solicitada en 1690 por la Diputación aragonesa. Como respuesta a estos obstáculos, si ya las Cortes de 1684-86 prohibieron importar vino navarro, la Diputación en 1691-92 y las Cortes de 1702 intentaron vetar todo comercio en Aragón con este reino.

so LATORRE, José Manuel: «La producción agraria...», pp. 138, 145 y MORENO ALMARCEGUI, Antonio: «Población y producción...» p. 493.

51 AMZ, Act. Mun., 1616, 8 de enero y 9 de octubre y Caja 14, sign. 2/3/1.

52 SALAS, José Antonio: La población ... pp. 109, 118-119.

53 Mateos, José Antonio: Auge... p. 347 y AMZ, Act. Mun., 1577, 18 de septiembre, 1614, 13 de septiembre, 1644, 9 de marzo y Caja 14, sign. 2-3-19. La producción de vino en la comarca de Cariñena durante la segunda mitad del siglo XVIII, en DiARTE, Pascual: La Comunidad... pp. 167-170. 
cias a sus mejores precios que movieron a los consumidores a su adquisición pese a incumplir la normativa municipal que protegía a los viticultores locales. La emergencia de una mayor especialización regional en la producción de vino y aceite se plasmó en el amplio radio de acción abarcado por los arrieros procedentes de las comarcas más competitivas, como los «aceiteros» o «arroberos» de Calatayud y Saviñán o del Bajo Aragón ${ }^{54}$. En ciudades del sur del reino como Daroca o Albarracín, carentes de olivares por razones climáticas, la debilidad financiera municipal extremó la dependencia hacia estos arrieros y forzó a aceptar mayores subidas de precio en el mercado al apreciarse síntomas de escasez.

\section{CUADRO 1. COEFICIENTES DE CORRELACION DE LOS PRECIOS DEL TRIGO EN DAROCA, ZARAGOZA Y FRAGA (SIGLO XVII)}

\begin{tabular}{|c|c|c|c|}
\hline $\begin{array}{c}\text { POBLACIONES } \\
\text { CONTRASTADAS }\end{array}$ & $\begin{array}{c}\text { PERÍODO } \\
\text { COMPARADO }\end{array}$ & $\begin{array}{c}\text { AÑOS CON DATOS } \\
\text { DISPONIBLES }\end{array}$ & $\begin{array}{c}\text { COEFICIENTE } \\
\text { DE CORRELACIÓN }\end{array}$ \\
\hline Daroca-Fraga & $1601-52$ & 21 & 0,81 \\
\hline Fraga-Zaragoza & $1601-52$ & 20 & 0,82 \\
\hline Daroca-Zaragoza & $1601-52$ & 33 & 0,63 \\
\hline Daroca-Fraga & $1653-1705$ & 35 & 0,47 \\
\hline Fraga-Zaragoza & $1653-1705$ & 29 & 0,62 \\
\hline Daroca-Zaragoza & $1653-1705$ & 40 & 0,78 \\
\hline
\end{tabular}

Fuentes: Sobre Daroca, Mateos, José Antonio: Auge... pp. 494-497. Para Fraga, Berenguer, Antonio: «Un ejemplo...» p.245 y OTERO, Félix: La Vila... vol. 1, p.144. Sobre Zaragoza, AMZ, Act. Mun., 1513-1697, Bastardelos, 1550-1706, Libros de contratos de la ciudad (795) y contabilidad del pósito y de las panaderías en Cajas 479, 480, 481,482, 492, 495, 7765 y 7887 (elaboración propia).

Como sucede en las transacciones interregionales, la emergencia de una especialización agrícola de Aragón revela la lenta y parcial conformación de un mercado local y comarcal menos «autocentrado». La mayor complementariedad de la producción y comercialización de productos agrarios entre distintas zonas inicia un lento proceso de integración del mercado regional, acelerado al crecer la demanda interna y externa de materias primas en el siglo XVIII. Libre de los controles impuestos por los concejos al vino o al aceite en el mercado local, el comercio de grano parece adquirir especial fluidez y eficiencia en la segunda mitad del Seiscientos al descender la intervención pública y aumentar

54 Mateos, José Antonio: Auge... pp. 358, 363-364 y AMA, Libros de Mayordomía, 16211654. Las ventas de arrieros en el mercado público sin mediación de la Cámara municipal supusieron en 1700 y 1701 un 77,50\% y un 78,35\% del suministro de Daroca. La difusión del aceite de Alcañiz en las aldeas de la Comunidad de Daroca en el siglo XVIII se confirma en DiARTE, Pascual: La Comunidad... p. 220. 
la demanda externa. Por desgracia, la fragmentación de las series de precios existentes en Aragón y la deformación provocada por la fuerte presión fiscal municipal sobre la carne en el Seiscientos han impedido contrastar este proceso entre los distintos productos agrarios. Con todo, los precios expuestos en el gráfico 2 resultan indicativos sobre el desarrollo del mercado regional de trigo.

La posible tendencia del mercado regional de grano hacia una mayor integración ha sido estimada mediante el cálculo del coeficiente de correlación entre los precios de Zaragoza, Daroca y Fraga en el siglo XVII, divididos en dos períodos: 1601-52 y 1653-1705. Constatación preliminar, los precios disponibles para Barbastro durante 1630-91 deben desestimarse para el cálculo por corresponder a ventas de trigo por el pósito que incluyen un fuerte gravamen municipal y no reflejan las fluctuaciones del mercado ${ }^{55}$. Los resultados, expuestos en el cuadro 1, requieren matizaciones. El elevado índice de correlación detectado en los precios de Fraga con los de Daroca y Zaragoza para 1601-52 resulta más aparente que real al hallarse representados en exceso en los tres casos los años de carestía que elevan los precios del grano y ocluyen las diferencias más marcadas en años normales. Por este motivo, pese a ser mercados más próximos, la mayor amplitud de la muestra provoca un coeficiente de correlación más bajo entre Daroca y Zaragoza. Mejor documentado para los tres núcleos al aumentar los datos e incluir una mayoría de años de buenas cosechas, el período 1653-1705 muestra unos índices de correlación más coherentes al aumentar conforme crece la cercanía entre los tres mercados. A la espera de confirmar esta hipótesis con investigaciones sobre la evolución de los precios aragoneses en el siglo XVIII, el aumento del coeficiente de correlación entre Daroca y Zaragoza en la segunda mitad del Seiscientos frente al estimado para la primera mitad parece avalar cierta tendencia a una mayor integración del mercado regional de grano cuya dimensión sería conveniente precisar.

Limitada por su débil demanda interna, la especialización en materias primas que caracteriza la producción económica aragonesa del Seiscientos se afirmó gracias a su mayor comercialización exterior. El descenso del precio del trigo y aceite durante la segunda mitad de la centuria — véase los gráficos 2 y 3 - restringió las trabas a su exportación por parte de la Diputación y otras

55 SALAS, José Antonio: La población... pp. 177-184, 348. La sobrestimación de los precios del trigo expuestos en la serie pudo haberse detectado si su evolución se hubiera contrastado con la remodelación del mercado y abasto público de cereal sufrida durante el Seiscientos, sobre todo en su segunda mitad. Iguales indicios hubieran aportado la comparación de los precios de compra y venta de grano por el pósito o el análisis de sus transferencias de dinero a la caja central del concejo a través de la contabilidad municipal. Así, resulta imposible que cualquier población aragonesa subsista tantos años con valores del trigo en el mercado muy superiores a los noventa sueldos por cahíz: desde las Cortes de 1626, el alcance de este precio en el Almudí de Zaragoza era considerado síntoma de escasez de grano y provocaba que la Diputación prohibiese su exportación del reino. Tampoco es factible que estos precios se mantengan en Barbastro tan altos durante la segunda mitad de siglo tras haber caído la demanda de trigo en Aragón. 
autoridades públicas y facilitó a las elites un uso más eficiente de sus excedentes $^{56}$. Junto a la exportación de trigo y carne hacia Valencia o de lana y aceite hacia Francia habitual en Aragón durante el siglo XVII ${ }^{57}$, Cataluña incrementó su demanda de materias primas, antes incluso de iniciarse su expansión manufacturera y comercial a fines de la centuria. Debilitada su economía y población tras la guerra de la Secesión (1640-52), este aumento no sólo respondió al abasto de Barcelona sino a la presencia del ejército castellano en el Principado durante el conflicto, su acuartelamiento posterior para vigilar la frontera y el incremento de sus efectivos ante las sucesivas guerras (1635-59, 1667-68, 1674-78, 1683-84, 1689-97) con Francia. La decisión tomada por Felipe IV en 1642 de que los abastecedores de su ejército estacionado en Aragón o Cataluña no pagasen tasas aduaneras ni peajes de tránsito en el reino aragonés por considerarse estos bastimentos como patrimonio real se mantuvo durante la centuria e incrementó las transacciones interregionales ${ }^{58}$. Si bien esta prerrogativa real había sido ejercida con anterioridad, nunca había afectado a un tráfico de mercancías tan importante y constante. Los contrastos con los asentistas apuntan hacia un suministro anual de unos 70.000 cahíces de grano - la mitad o los dos tercios solía ser cebada y el resto trigo- en años de paz para suponer unos 90.000 cahíces en períodos de guerra y crecer más si las hostilidades tenían lugar en el Principado: entre 132.000 y 138.000 cahíces catalanes en 16939759. Las continuas quejas efectuadas por la Diputación como beneficiaria de las aduanas del reino y por sus arrendatarios ${ }^{60}$, quienes señalaron ante el Consejo de Aragón las posibilidades de defraudar abiertas a comerciantes y asentistas con estas exenciones, resultaron inútiles frente a los apuros de la hacienda real a pesar de constatarse el fuerte contrabando desatado en las fronteras por la presencia de ambos ejércitos.

No ha sido posible estimar el monto anual de las exportaciones de cereales y otras materias primas aragonesas destinadas al ejército castellano, ya que los asentistas se abastecían en ambas Coronas de Aragón y Castilla y la exención arancelaria regía en ambos territorios para las mercancías forasteras. Se halla documentado así el tránsito de grano castellano a través del río Ebro en este período. No obstante, la conveniencia de reducir los costosos gastos del transporte por tierra desde Castilla facilitó que asentistas y comisionados adquirieran gruesas cantidades de trigo y cebada en Aragón ${ }^{61}$. En años de seria necesidad de abasto para Barcelona y el ejército, la Diputación, la ciudad de Zaragoza y otras autori-

56 PeIRÓ, Antonio: «Comercio de trigo...» pp. 38-42.

57 REDONDO, Guillermo: «Las relaciones comerciales...» y CASEY, James: El reino de Valencia en el siglo XVII, Madrid, 1983, pp. 81-103.

58 ACA, CA, legajos 57-60.

59 ACA, CA, legajos 57-60 y 66 y AMZ, Act. Mun., 1680, 23 de noviembre, fol.536r-538r.

60 ACA, CA, legajos 59 y 74-76 y SANZ CAMAÑES, Porfirio: Política, hacienda y milicia en el Aragón de los últimos Austrias entre 1640 y 1680, Zaragoza, 1997, pp. 158-159, 195, 281-282.

61 ACA, CA, legajos 57-60 y AMZ, Act. Mun., 1653, 15 de enero. 
dades públicas aragonesas permitieron extraer grano nativo y forastero a pesar de haber rebasado su valor en el Almudí de la capital - 1652, 1678- el máximo fijado en las Cortes aragonesas de 1626 para prohibir su exportación: en 1677 las propias Cortes concedieron la licencia tras haberse proclamado ya la veda ${ }^{62}$. En ocasiones, el concejo de Zaragoza prestó dinero al monarca como censales a nombre del asentista para garantizar el suministro de grano al ejército ${ }^{63}$. De forma más moderada, este proceso parece extenderse a otros productos agrarios como la carne. Si bien la monarquía estipuló en algunos contratos con los asentistas la obligación de adquirir en Castilla los ganados para alimentar al ejército, su arriendo ocasional por mercaderes zaragozanos y el recurso a comprar vacas y corderos aragoneses en años de escasez hacen suponer un aumento de la exportación de reses al Principado ${ }^{64}$. Por este motivo, la Casa de Ganaderos de Zaragoza suplicó en 1699 a la Diputación derogar la veda de exportar ganados del reino dictada tras padecer éstos una seria epidemia en 1694-95 para poder venderlos en Cataluña y no tener que rebajar su precio en Aragón ${ }^{65}$.

Este aumento del tráfico interregional vinculado a la demanda del ejército se vio afianzado gracias la recuperación demográfica y expansión manufacturera y comercial catalana en las décadas finales del Seiscientos ${ }^{66}$ para continuar durante el siglo XVIII. Tras finalizar la guerra de Sucesión y derogarse en 1717 las aduanas interiores ${ }^{67}$ en las Coronas de Castilla y Aragón, incluidas las existentes entre los distintos reinos que componían esta última, el mayor crecimiento económico y demográfico del Principado aumentó las exportaciones de cereal y carne aragoneses, así como de su lana y aceite ya en la segunda mitad de la centuria, en especial hacia Barcelona ${ }^{68}$. Jerónimo de Uztáriz constató

62 ACA, CA, legajos 76 y 89. La Diputación prohibió exportar grano de Aragón en 1651, 1654, 1660, 1664, 1677 y 1683. Véase GómEZ ZorraQuino, José Ignacio: Zaragoza... p. 20, PeIró, Antonio: «Comercio de trigo...» pp. 40-42 y SANZ Camañes, Porfirio: Política... pp. 168$169,180,185,323$.

63 ACA, CA, legajos 57-60 y 66 y AMZ, Act. Mun., 1695, 23 de noviembre, fol.536r-538r.

64 ACA, CA, legajos 57-59 y 74 y AMZ, Caja 7797, sign. 44-1, doc. 24.

65 Archivo de la Casa de Ganaderos de Zaragoza, Caja 260, ligamen 142, doc. 13 y AMZ, Act. Mun., 1695, 10 de marzo, 27 de junio. En su solicitud, la Casa de Ganaderos cifraba la cabaña lanar aragonesa en 359.544 cabezas en 1699. Sin incluir el partido de Benabarre, el Consejo de Aragón en 1714 estimaba 408.933 reses, según CASTÁN, José Luis: Pastores... pp. 201-203.

66 VILAR, Pierre: Cataluña en la España Moderna, vol.1, Barcelona, 1978, pp. 430-452 y ANDREU, Jordi y SIMON, Antoni: «La población de Barcelona en los siglos XVI y XVII. Una aproximación», en NADAL, Jordi (ed.): La evolución demográfica bajo los Austrias, Alicante, 1991, pp. 262-263.

67 Sobre el carácter del incompleto desarme arancelario entre Aragón y Cataluña en el siglo XVIII y sus consecuencias para el tráfico interregional, TORRAS, Jaume: «Relaciones económicas...», pp. 17-31.

68 PeIró, Antonio: «Comercio...» pp. 51-59 y GómeZ ZORRAQUINO, José Ignacio: «Las relaciones mercantiles entre Aragón y Cataluña en el siglo XVIII», en Las relaciones económicas entre Aragón y Cataluña (siglos XVIII-XX), Huesca, 1990, pp. 70-73 y «La expansión de las redes comerciales catalanas por Aragón durante el siglo XVIII», en Els catalans a Espanya, 1760-1914, Barcelona, 1996, pp. 260-261. 
ya en 1724 el incremento y mayor complementariedad de los intercambios interregionales al observar que la escasez de grano y ganado en Cataluña se suplía con importaciones de Aragón y Castilla en sustitución de las antes realizadas desde Francia y Berberia ${ }^{69}$, compras compensadas con los mayores beneficios generados por las ventas de productos textiles por catalanes en el interior peninsular. Si los mercaderes del Principado se instalaron en Aragón ya en la primera mitad de siglo, su asunción de las principales transacciones del reino a partir de 1770 en sustitución de los comerciantes franceses y navarros no hizo sino reforzar este proceso ${ }^{70}$.

\section{LA HACIENDA MUNICIPAL EN EL SIGLO XVII.}

En contraste con el siglo anterior, el Seiscientos asistió a un retroceso del control municipal no sólo sobre el mercado, sino sobre su hacienda ${ }^{71}$. La incapacidad de allegar ingresos para afrontar los crecientes gastos durante la segunda mitad del Quinientos se agravó en el siglo XVII hasta volver insuficiente el perpetuo recurso al crédito. Al tiempo que la propiedad de la deuda censal fue transferida por ciudadanos e infanzones al clero mediante ventas o donaciones, los concejos firmaron desde fines del siglo XVI concordias con sus acreedores para demorar pagos o reducir la tasa de interés y poder afrontar sus deudas. Su revisión confirió la gestión de las haciendas a «conservadores» designados por los censalistas tras garantizar éstos a los concejos el mantenimiento de su administración política y judicial, los propios y comunales. Orientada a asegurar el sufragio de pensiones y la luición de censales, esta gestión no saneó con rapidez unas haciendas municipales que reflejan una clara debilidad en la primera mitad del Setecientos. Al restringir el poder municipal, propició constantes pleitos entre concejos y Juntas de censalistas — con fuerte predominio del clero—, sobre la gestión de propios, el uso de comunales o la regulación del mercado.

Sobre este esquema, el creciente endeudamiento de muchos concejos ya a principios del siglo XVII impuso introducir «arbitrios» temporales, muchos de los cuales se consolidaron como ingresos permanentes ${ }^{72}$. Consistieron en mo-

69 UzTáRIZ, Jerónimo de: Teórica y Práctica de Comercio y de Marina, Madrid, 1968, edición facsímil del original impreso en Madrid en 1742, p. 139.

70 GÓmEZ ZORRAQUiNO, José Ignacio: «La burguesía mercantil catalana y su presencia en Aragón (1770-1808)», en Pedralbes, (Barcelona), 8-I, pp. 405-423, «Las relaciones mercantiles...», pp. 65-76 y «La expansión...», pp. 255-269; PÉREZ SARrión, Guillermo: «Compañías y redes mercantiles rurales en Aragón a fines del Antiguo Régimen: una aproximación microanalítica», en Els catalans a Espanya, 1760-1914, Barcelona, 1996, pp. 271-284.

71 SAlas, José Antonio: «Las haciendas...», pp. 11-66 y MATEOS, José Antonio: «Propios, arbitrios...», pp. 51-77.

72 IngladA, Jesús: Estudio... pp. 246-248, 257; Mateos, José Antonio: Auge... pp. 130-133 y AMA, doc. 152 . 
nopolios sobre productos elaborados como la nieve, el tabaco, los naipes, el aguardiente, el jabón, el hierro o el carbón. Justificados en algunos casos por su carácter superfluo o perjudicial, la incidencia de otros en el consumo diario fue notable. Las derramas repartidas entre los vecinos crecieron para financiar reformas urbanísticas o la incipiente asistencia médica estable introducida en Aragón desde el segundo cuarto del siglo XVII, práctica que costó a veces la oposición de los estamentos privilegiados ${ }^{73}$.

Expresión del declive financiero, nuevos tributos fueron sancionados para pagar pensiones o luir censales. Esta opción se adoptó ya en el último tercio del siglo XVI en núcleos bajo dominio laico o eclesiástico donde se mezclaban las negociaciones del endeudamiento de concejos y señores al ceder éstos a sus censalistas derechos sobre los vasallos en las concordias. Una mayor redefinición del marco impositivo municipal se inició en Aragón a principios del siglo XVII, precipitada en núcleos de señorío por la expulsión de los moriscos ${ }^{74}$. Prueba de su importancia, las Cortes de 1626 y 1646 regularon esta negociación y redujeron la tasa de interés sobre los censales municipales. Con frecuencia a través del Consejo de Aragón, las concordias entre concejos y acreedores fueron sometidas al refrendo del monarca a lo largo del siglo.

Entre dichas imposiciones, una opción era la fiscalidad directa ${ }^{75}$. Consistía con frecuencia, como sucedía desde fines del siglo XVI en lugares de señorío, en la entrega anual de una parte de las principales producciones agrarias por los vecinos. Caspe estableció en 1615 el quinceno del ganado lanar y la producción de cereal, vino o aceite, más tasas sobre la producción artesanal y corretajes sobre la seda o el azafrán. En ocasiones, los impuestos se distribuyeron según la hacienda particular: los concejos de Molinos en 1644 y Bujaraloz en 1717 pactaron con sus acreedores tributaciones temporales para pagar pensiones de censales. Más usuales en pequeñas localidades, los impuestos según hacienda eran rechazados por los sectores pudientes. Las cuotas sobre la cosecha afectaban a propietarios o arrendatarios de tierras en favor de otros grupos profesionales o rentistas. En ambos casos, la exención de los estamentos privilegiados y las dificultades para estimar la base imponible entre los vecinos pecheros generaron tensiones y demoras. Como revela el rápido abandono del onceno aplicado en Barbastro y Tamarite de Litera para extinguir censales en la primera mitad de la centuria, estos problemas reducían la rentabilidad y continuidad de dichas cargas.

\footnotetext{
73 Otero, Félix: La Vila... vol.1, pp. 113-114; Mateos, José Antonio: Auge... pp. 151-153, 470.

74 ABADIA, Alejandro: La enajenación... pp. 56-58, 195-198, 249-256, 282-283 у 294; MATEOS, José Antonio: «Propios, arbitrios...» pp. 70-72.

75 COLAS, Gregorio: La bailía de Caspe en los siglos XVI y XVII, Zaragoza, 1979, pp. 139-140, 209213; SAnZ CAmaÑES, Porfirio: «La crisis de la hacienda municipal en la villa de Molinos», en Teruel, (Teruel), 82, 2, (1991), pp. 69-85; SALAS, José Antonio: «De la euforia...», pp. 31, 49-50; SANZ LEDESMA, Joaquín: "Contrato pactado entre censalistas y la villa de Monzón en el año 1629», en Cuadernos, (Monzón), 21, (1994), p. 131 y AMZ, Act. Mun., 1638, 30 de octubre y Libro 1073, fol.3.
} 
La segunda posibilidad era la fiscalidad indirecta ${ }^{76}$, de más fácil recaudación y ligada por tradición a la fiscalidad real y al sufragio extraordinario de obras de interés común: concejos afectados por la peste bubónica a mediados del siglo XVII - Jaca, Huesca, Zaragoza, Borja- introdujeron sisas vecinales, aplicables a todos los estratos, para recuperar los costes asistenciales de la epidemia. Con todo, si bien Calatayud o Daroca adoptaron sisas desde inicios del Seiscientos para luir censales, su continuidad fue frenada por la fiscalidad real en 1628-52 y su difusión entrañó serios problemas: tanto si afectaban sólo a vecinos pecheros como si incluían a los exentos, requerían la obtención de permisos temporales del rey o del papa. Como demuestra su aplicación continua en Daroca durante el Seiscientos - véase el Gráfico 1-o su adopción por Jaca y Zaragoza para reducir sus deudas en la segunda mitad de siglo, las sisas arraigaron en las ciudades. Allí su carácter indirecto suscitó el interés de la oligarquía municipal; pero promovió la oposición de la nobleza y clero o la exigencia de su negociación: las licencias papales para cargar sisas destinadas a cancelar censales conllevaban así la exención de los privilegiados, en especial del clero. Su seria incidencia en el consumo generó idéntico rechazo en los grupos más humildes. Reflejo de estos intereses contrapuestos, al ceder sus propios a fines del siglo XVII y principios del XVIII, ciertas elites ciudadanas pactaron con los acreedores cargar sisas anuales para luir censales ${ }^{77}$. Por el contrario, representantes de labradores y artesanos se opusieron a prolongarlas tras expirar su licencia y defendieron su sustitución por tributaciones directas ${ }^{78}$.

Al margen de vender tierras comunales, práctica adoptada por los concejos al acercarse o producirse su quiebra definitiva ${ }^{79}$, la procura de mayores ingresos impuso desde fines del siglo XVI gravar más los corretajes y monopolios de venta sobre los principales alimentos, en especial sobre el pan y la carne, artículos que permitían una mayor detracción. Según se ha constatado en distintos núcleos - Barbastro, Daroca, Zaragoza, Albarracín-, con las salvedades impuestas por las mayores carestías de trigo, la gestión se encaminó a drenar dinero desde el pósito, la cámara de aceite y la administración de la carne hacia la caja central para frenar su déficit permanente ${ }^{80}$. Como revela el ejemplo de Zarago-

76 Sanz Camañes, Porfirio: Política... pp. 180-182, 292; Mateos, José Antonio: Auge... pp. 140-144 y «Municipio y mercado en el Aragón moderno: el abasto de carne...» p. 212 y URZAY, J. Ángel, SANGÜESA, Antonio, e IBARRA, Isabel: Calatayud... p. 150. La aplicación de sisas por los concejos aragoneses tras el azote de la peste bubónica en MAISO, Jesús: La peste aragonesa de 1648 a 1654, Zaragoza, 1982, pp. 176-180. El interés de las elites locales por aplicar impuestos indirectos durante el siglo XVII, sobre todo en las ciudades, se evidencia para las Coronas de Aragón y Castilla en Fiscalitat estatal... y GUTIÉRREZ AlONSO, Adriano: „Ciudades y monarquía...» pp. 209-210.

77 Mateos, José Antonio: Auge... p. 144 y AHPZ, Real Acuerdo, Sección Concordias, Partido de Huesca, 1745, Expediente 13.

78 Mateos, José Antonio: Auge... pp. 141-144 y AHPZ, Real Acuerdo, Partido de Teruel, 1724, Expediente 2 y 1728, Expediente 13.

79 Mateos, José Antonio: «Propios, arbitrios...», pp. 60-61.

80 Salas, José Antonio: La población... pp. 82-85; MAteOS, José Antonio: Auge... pp. 183-186, 293-299, 313-323, «Municipio y mercado en el Aragón moderno: el abasto de trigo en Zaragoza 
za en los cuadros 2 y 3 , su práctica creciente desde fines del siglo XVI y principios del XVII corrió pareja al endeudamiento municipal.

CUADRO 2. TRANSFERENCIAS DE DINERO POR EL POSITO A LA MAYORDOMIA DE ZARAGOZA DESTINADAS AL PAGO DE PENSIONES DE CENSALES (1581-1697) —EN SUELDOS-

\begin{tabular}{|c|c|c|c|c|c|}
\hline AÑO & CANTIDAD & AÑO & CANTIDAD & AÑO & CANTIDAD \\
\hline 1581 & $20.000 s$ & 1601 & $100.000 \mathrm{~s}$ & 1620 & $220.910 \mathrm{~s}$ \\
\hline 1582 & $20.000 \mathrm{~s}$ & 1605 & $141.290 \mathrm{~s}$ & 1623 & $232.725 \mathrm{~s}$ \\
\hline 1583 & $20.000 \mathrm{~s}$ & 1606 & $141.290 \mathrm{~s}$ & 1624 & $232.726 \mathrm{~s}$ \\
\hline 1586 & $20.000 \mathrm{~s}$ & 1607 & $141.290 \mathrm{~s}$ & 1627 & $266.626 \mathrm{~s}$ \\
\hline 1587 & $20.000 \mathrm{~s}$ & 1610 & $141.290 \mathrm{~s}$ & 1651 & $453.898 \mathrm{~s}$ \\
\hline 1588 & $20.000 \mathrm{~s}$ & 1612 & $141.290 \mathrm{~s}$ & 1661 & $518.759 \mathrm{~s}$ \\
\hline 1591 & $100.000 \mathrm{~s}$ & 1613 & $141.290 \mathrm{~s}$ & 1666 & $560.000 \mathrm{~s}$ \\
\hline 1594 & $100.000 \mathrm{~s}$ & 1616 & $205.884 \mathrm{~s}$ & 1697 & $251.030 \mathrm{~s}$ \\
\hline 1598 & $100.000 \mathrm{~s}$ & 1617 & $208.839 \mathrm{~s}$ & & \\
\hline
\end{tabular}

Fuentes: AMZ, Libros de Mayordomía, (709-782)

CUADRO 3. TRANSFERENCIAS DE DINERO POR LA ADMINISTRACIÓN DE LA CARNE A LA MAYORDOMIA DE ZARAGOZA DESTINADAS AL PAGO DE PENSIONES DE CENSALES (1551-1651) —EN SUELDOS-

\begin{tabular}{|c|c|c|c|c|c|}
\hline AÑO & CANTIDAD & AÑO & CANTIDAD & AÑO & CANTIDAD \\
\hline 1554 & $10.000 \mathrm{~s}$ & 1591 & $80.000 \mathrm{~s}$ & 1613 & $201.852 \mathrm{~s}$ \\
\hline 1568 & $15.500 \mathrm{~s}$ & 1594 & $80.000 \mathrm{~s}$ & 1616 & $214.075 \mathrm{~s}$ \\
\hline 1569 & $18.000 \mathrm{~s}$ & 1598 & $80.000 \mathrm{~s}$ & 1617 & $208.930 \mathrm{~s}$ \\
\hline 1581 & $22.000 \mathrm{~s}$ & 1601 & $80.000 \mathrm{~s}$ & 1620 & $220.912 \mathrm{~s}$ \\
\hline 1582 & $30.000 \mathrm{~s}$ & 1605 & $173.052 \mathrm{~s}$ & 1623 & $232.725 \mathrm{~s}$ \\
\hline 1583 & $30.000 \mathrm{~s}$ & 1606 & $173.052 \mathrm{~s}$ & 1624 & $232.726 \mathrm{~s}$ \\
\hline 1586 & $30.000 \mathrm{~s}$ & 1607 & $173.052 \mathrm{~s}$ & 1627 & $266.626 \mathrm{~s}$ \\
\hline 1587 & $30.000 \mathrm{~s}$ & 1610 & $173.052 \mathrm{~s}$ & 1635 & $403.841 \mathrm{~s}$ \\
\hline 1588 & $30.000 \mathrm{~s}$ & 1612 & $158.751 \mathrm{~s}$ & 1651 & $573.668 \mathrm{~s}$ \\
\hline
\end{tabular}

Fuentes: AMZ, Libros de Mayordomía, (723-769) y Caja 209, no 8-10-2.

(siglos XVI y XVII)», en Espacio, Tiempo y Forma, (Madrid), IV, 15, pp. 44-45, «Municipio y mercado en el Aragón moderno: el abasto de carne...» pp. 189, 199 y «La hacienda municipal de Albarracín en el siglo XVII: crisis, endeudamiento y negociación», en Teruel, (Teruel), 88-89, 2 (2000-2002), pp. 188-190 y AMA, doc.147, contabilidad del pósito, 1650-1711. 
Si bien estas transferencias no evitaron la quiebra de la caja central, obligaron a abandonar el sustento de la demanda y la contención de precios practicados por estas administraciones subsidiarias en el Quinientos ${ }^{81}$. Se restringió el stock comercializado por pósitos, cámaras de aceite y carnicerías, sobre todo al descender en Aragón los precios agrarios en la segunda mitad del siglo XVII — véase los Gráficos 2, 3 y 5 y los cuadros 4, 5 y 6-, y se impuso una gestión más rentable que contrajo una demanda interna ya castigada por el declive demográfico y económico. Si bien sus efectos perjudiciales sobre el consumo fueron moderados por este descenso de los precios, la menor capacidad municipal de afrontar carestías se dejó sentir. La comparación de los precios del aceite en Daroca y Zaragoza a fines del siglo XVII en el Gráfico 3 evidencia tanto la debilidad municipal como las limitaciones de suministro aún presentes en el mercado regional al mostrar una mayor incidencia local de la escasez en las producciones más deficitarias. Con las salvedades impuestas por la defensa del productor local, el menor control público sobre el mercado potenció los tratos privados, la especialización agraria y un funcionamiento algo más eficiente del mercado regional.

La demanda de mayores ingresos y la inflación de precios forzó a muchos concejos a fines del siglo XVI y principios del siglo XVII a sustituir el arriendo de los principales abastos por su administración. Esta práctica cobró especial fuerza en 1620-50 hasta consolidarse la vuelta al arriendo en la segunda mitad de la centuria tras descender el precio de los productos agrarios ${ }^{82}$. La gestión municipal del pósito y las carnicerías facilitó el cobro de sisas destinadas a pagar las fuertes demandas fiscales de la monarquía en 1628-52. Con todo, el mayor gravamen aplicado al trigo y la carne continuó en cierto grado durante la segunda mitad de la centuria en beneficio de la hacienda municipal tras cesar servicios y levas o volverse al sistema de arriendo. Fijados sobre la carne, trigo, vino y aceite como tributo real temporal en 1628-52, sisas y corretajes fueron retomados con posterioridad para sufragar pequeños donativos o servicios al monarca y se consolidaron a veces como ingresos del concejo ${ }^{83}$.

La administración de corretajes y monopolios permitió a la oligarquía concejil introducir impuestos sin recurrir a la negociación con instancias superiores, censalistas u otros grupos sociales. La lógica protesta de los estratos privilegiados no se demoró y alcanzó gran virulencia en ciudades - Huesca, Zaragoza, Daroca- donde los tributos sobre el trigo, la carne y a veces el vino generaban sumas importantes ${ }^{84}$ : caso extremo, el abasto de la carne aportó en Zaragoza al

81 Mateos, José Antonio: Auge... pp. 295-299, 360-364, «Municipio y mercado en el Aragón moderno: el abasto de trigo...» pp. 46-49 y «Municipio y mercado en el Aragón moderno: el abasto de carne...» pp. 200-201, 212-213 y «Control público, mercado...» pp. 27-31.

82 Véase la nota 80 y COLAS, Gregorio y SALAS, José Antonio: «Repercusiones económicas y sociales en Zaragoza del pago de la sisa de 1626», en Estudios, (Zaragoza), 78, (1978), pp. 151-168.

83 SAnZ Camañes, Porfirio: Política... pp. 131, 182, 293-296.

84 IngladA, Jesús: Estudio... pp. 186-190; Mateos, José Antonio: Auge... pp. 322-323, «Municipio y mercado en el Aragón moderno: el abasto de trigo...» pp. 55-56 y «Municipio y mercado en el Aragón moderno: el abasto de carne...» pp. 189, 206, 209-212. 
concejo en 1651-95 unos ingresos medios anuales de 741.040 sueldos, un $1.215,84$ por ciento superiores a los 56.317 sueldos obtenidos en 1550-94. Amparados por la normativa foral, estos estamentos exigieron su exención y se unieron a los restantes vecinos en su oposición a estas cargas. De gran importancia fue la negativa del clero, que unió a su poder económico e influencia social la jurisdicción privilegiada de iglesias y conventos, erigidos en centros de defraudación que limitaban el control municipal del mercado. La lucha legal iniciada a mediados de siglo por el Cabildo catedralicio de Zaragoza frente a la fuerte presión fiscal municipal concluyó incluso con su completa victoria al obtener en 1722-24 licencias de Felipe V para instalar sus propias carnicerías destinadas al consumo del clero urbano.

GRÁFICO 4. EVOLUCION DE LOS INGRESOS POR MONOPOLIOS DE ABASTOS EN EL MUNICIPIO DE ALBARRACÍN (1621-54) —EN SUELDOS-

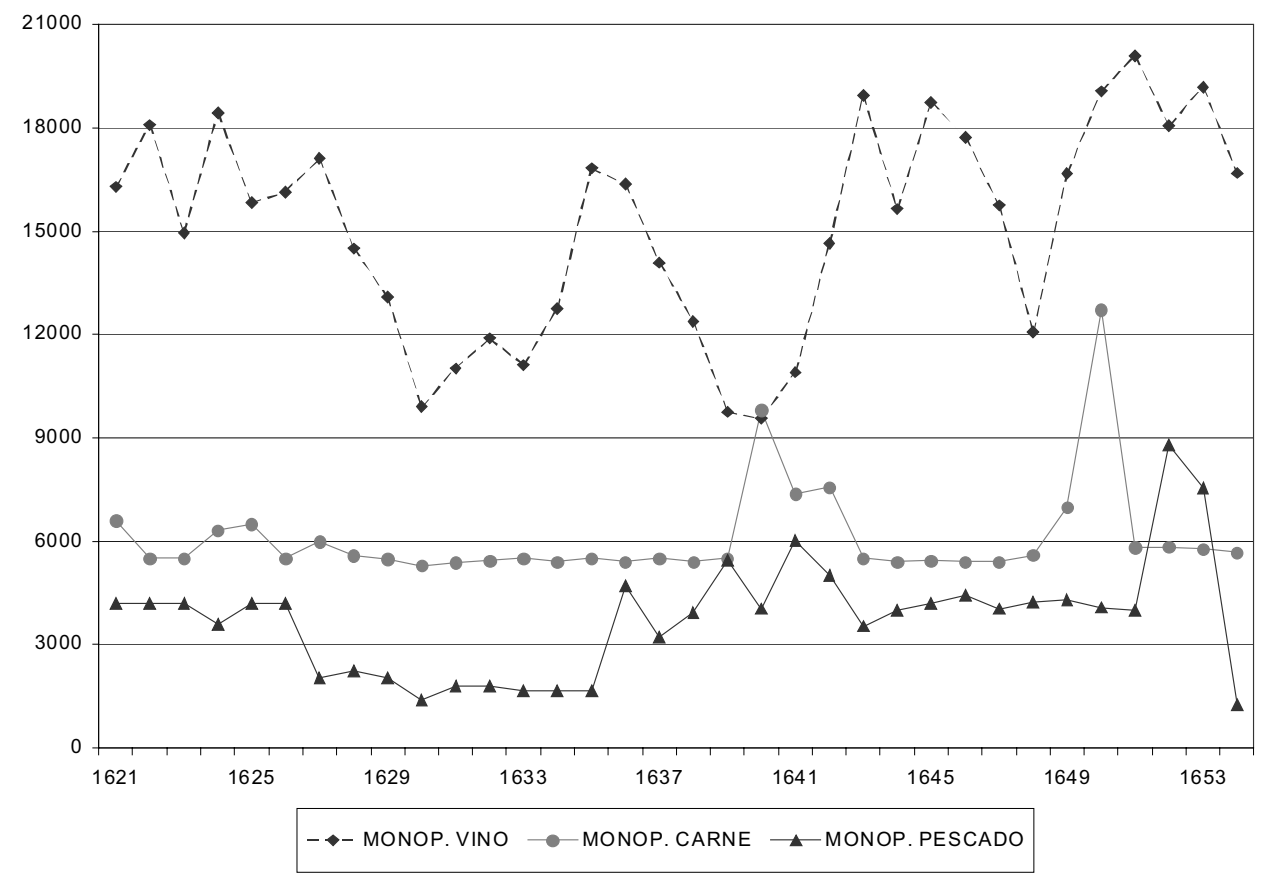

Fuentes: MATEOS, José Antonio: «La hacienda municipal de Albarracín...», p. 180.

Tanto a través de corretajes y monopolios de abastos como de tributos ligados al endeudamiento municipal, la presión fiscal aplicada sobre los principales productos agrarios por cada concejo guarda relación con su control sobre el mercado, los intereses económicos de las elites y la capacidad de presión veci- 
nal. Menos analizados, los pequeños núcleos contemplaron en mayor medida tributaciones directas según hacienda o cesiones parciales de las principales cosechas. Más conocidas, las ciudades optaron por impuestos sobre los abastos esenciales que se avenían mejor con los intereses de las elites municipales por su carácter indirecto, más fácil recaudación y mejor adaptación a estrategias de comercialización ligadas a las transformaciones del mercado agrario. Así, junto a la inelasticidad de su demanda interna, las mayores opciones exportadoras del trigo y la carne sancionarían desde mediados de siglo en ciudades como Zaragoza la aplicación de mayores gravámenes sobre estos productos ya iniciada a principios de la centuria. Sólo la presencia de fuertes intereses ganaderos ${ }^{85}$ en concejos con un endeudamiento moderado propició en núcleos carentes de otras especializaciones agrarias como Albarracín —véase el Gráfico 4- una modesta presión fiscal sobre la carne para preservar su demanda a costa de gravar artículos importados como el vino.

Frente al trigo y la carne, el aceite y el vino recibieron cánones más tenues y discontinuos en villas y ciudades durante el Seiscientos. Previsible dada su menor incardinación de estos impuestos en los propios, su escasa actualización en la segunda mitad de la centuria parece también ligada a estrategias favorables en su mayoría al productor tras caer la demanda interna en el mercado local, semejantes a la regulación municipal de los cultivos en función de su comercialización. En zonas deficitarias o con una producción de baja calidad, esta baja presión fiscal se orientaría bien a favorecer el abasto o moderar su precio, facilitar la salida de los excedentes en el mercado local y limitar la competencia de zonas con mayores ventajas comparativas en factores de producción. En zonas productoras, como se evidencia en el aceite, podría pretender bien evitar tentativas vecinales de fijar tributos proporcionales a la cosecha recogida o garantizar a la elite el consumo local o comarcal de excedentes con menor salida en mercados exteriores ${ }^{86}$. Junto a las dificultades de Barbastro para recaudar el onceno sobre la cosecha de olivas, resulta revelador el escaso peso del aceite en las sisas vecinales de Zaragoza o la demora municipal hasta 1669 para crear un monopolio de venta que generó ingresos muy modestos a fines del Seiscientos. Por el contrario, la creciente demanda de aceite habría permitido ya en el segundo cuarto del siglo XVIII crear impuestos indirectos sobre su molturación en pequeños núcleos del Bajo Aragón.

85 La dedicación ganadera de Albarracín destaca en los recuentos de la cabaña aragonesa citados en la nota 64. La participación de las elites locales del sur aragonés en la propiedad y el comercio de ganado lanar, muy notable en la Comunidad de Albarracín, en CASTÁN, José Luis: Pastores... pp. 204-211.

86 SALAS, José Antonio: «Las haciendas...», pp. 31, 49-50. Sobre Zaragoza, AMZ, Act. Mun., 1668, 5 de agosto, 1669, 26 de junio, 1672, 4 y 9 de noviembre y Libros de Mayordomía, (777782). Para el Bajo Aragón, AHPZ, Partido de Alcañiz, 1726, Expediente 45, 1729, Expediente 26 y 1732, Expediente 77. 
GRÁFICO 5. EVOLUCION DEL PRECIO DE VENTA DEL CORDERO EN LAS CARNICERIAS DE BARBASTRO, DAROCA Y ZARAGOZA (1523-1702) —EN DINEROS POR LIBRA-

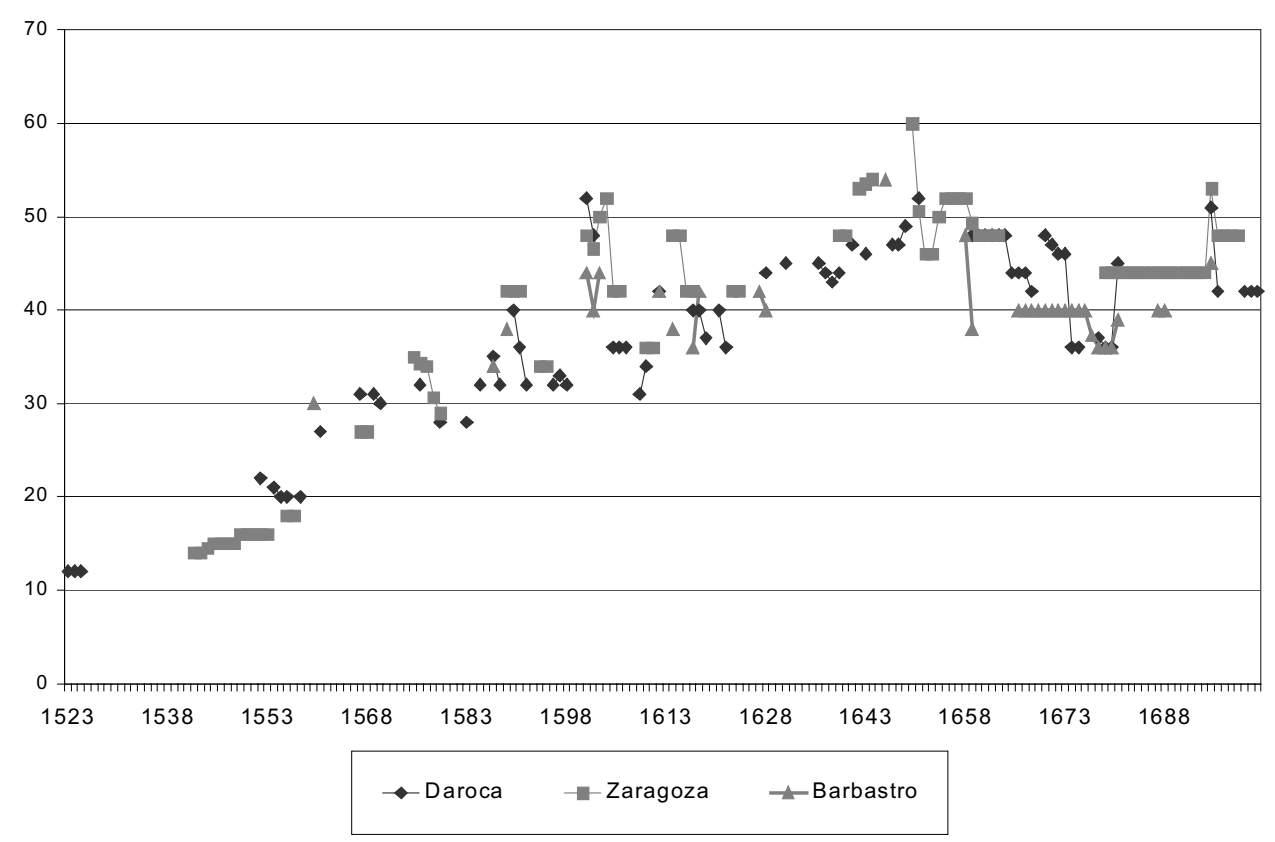

Fuentes: SALAS, José Antonio: La población... p. 92 y MATEOS, José Antonio: Auge... p. 498 y «Municipio y mercado en el Aragón moderno: el abasto de carne...» p. 197. Nota: la libra carnicera aragonesa incluye 36 onzas y equivale a $1.052,5$ gramos.

Como demuestran los estudios realizados sobre los abastos de carne y pescado, la mayor presión fiscal favoreció junto al declive demográfico y económico un descenso de la demanda en cantidad y calidad durante la segunda mitad de la centuria ${ }^{87}$. Con todo, la resistencia y defraudación vecinal matizaron esta incidencia al modificar la capacidad de consumo de la población, regulación pública del mercado y orientación de las cargas municipales. Su repercusión podía afectar a la evolución de los precios oficiales de ciertos productos agrarios, como revela el valor del cordero —denominado en la época carnero- en las carnicerías de tres ciudades aragonesas durante los siglos XVI y XVII expuesto en el Gráfico 5 y cuadro 6. Las menores posibilidades de autoabastecerse por los vecinos de Zaragoza y la participación parcial de la Casa de Ganade-

87 SALAS, José Antonio: La población... pp. 85, 123; Otero, Félix: La Vila... vol.1, p. 148; Mateos, José Antonio: Auge... pp. 321-322, 337 y «Municipio y mercado en el Aragón moderno: el abasto de trigo...", pp. 201-202, 213-214. 
ros en el monopolio de la carne provocaron que los muy elevados impuestos municipales redujesen el consumo de este producto en detrimento de los sectores más humildes ${ }^{88}$. En Daroca y Barbastro, ciudades más insertas en una economía agraria, una defraudación vecinal más efectiva propició un menor retroceso del consumo de carne y mayores descensos de su precio oficial que en la capital al forzar la rebaja de los gravámenes ${ }^{89}$. Por este motivo, la creación de carnicerías para el clero en Zaragoza en 1722-24 no sólo hundió los ingresos del concejo, sino su control del mercado local y la fuerte presión fiscal ejercida sobre la carne durante la mayor parte del Seiscientos.

\section{CONCLUSiOnes.}

En resumen, la gestión municipal realizada en Aragón durante el Quinientos contribuye a potenciar una producción agraria en ascenso por la vertebración de un modelo «autocentrado» de crecimiento económico iniciada ya en la Baja Edad Media. La moderación de los ingresos en los monopolios y corretajes concejiles sobre los principales productos agrarios y una mayor intervención pública sobre el mercado agrario mediante la creación de nuevas administraciones favoreció el abasto, sustentó la demanda interna e intentó reducir la inflación de precios para reactivar así la vida económica. Si bien esta intervención se revela efectiva en el trigo o la carne, la defensa del productor en el mercado local, la reticencia municipal a afrontar nuevos gastos y el menor consenso social para desarrollar mecanismos de contención de precios explica el modesto desarrollo de esta política para el vino o el aceite. En consecuencia, al limitarse la competencia de estos artículos en el mercado y extremarse su especulación en años de carestía, distintas ciudades sujetas a una fuerte demanda sufrieron crecientes problemas de abasto en las décadas finales de la centuria que se tradujeron en súbitas alzas de precios en detrimento de la población, con especial constancia en Zaragoza.

Sobre este esquema dado, la contracción demográfica y económica padecida en Aragón durante el Seiscientos generó una fuerte reestructuración del sector agrario, sobre todo en la segunda mitad de la centuria. Dentro de una economía aragonesa cada vez más orientada a importar manufacturas y exportar materias primas, la producción agraria se remodeló al contraerse la demanda interna. La mayor competencia resultante provocó una mayor especialización productiva en ciertas áreas, así como un mercado regional más eficiente. Esta remodelación parece iniciar un lento proceso de integración del mercado agrario que cobró especial vigor en el tráfico de trigo y se vio consolidado al aumentar la demanda de materias primas en el siglo XVIII. Propiciado al redu-

88 Mateos, José Antonio: «Municipio y mercado en el Aragón moderno: el abasto de carne...", pp. 208-213.

89 Salas, José Antonio: La población... pp. 84-85; Mateos, José Antonio: Auge... pp. 320-323. 
cirse la intervención pública y crecer la iniciativa privada en el mercado durante el Seiscientos, con mayor fuerza en su segunda mitad, este proceso se afianzó pese a la protección municipal del productor local. Junto a la lana exportada a Francia, la demanda de trigo y carne desde Cataluña y Valencia cimentó la especialización agropecuaria aragonesa y redujo el déficit comercial provocado por el declive industrial. El volumen e intensidad de las transacciones con Cataluña creció desde mediados del Seiscientos con nitidez gracias a la demanda generada por el ejército castellano, libre de tasas aduaneras, y por la expansión comercial y manufacturera del Principado a fines de siglo. La extroversión y especialización de la economía aragonesa ligada al desarrollo y complementariedad del tráfico interregional se agudizó durante el Setecientos tras desaparecer las aduanas interiores en las Coronas de Aragón y Castilla en 1717 y afirmarse el crecimiento económico y demográfico de Cataluña, con especial énfasis desde 1770 al asumir los comerciantes del Principado la dirección de los principales intercambios en Aragón.

Dado el fuerte peso de los impuestos sobre alimentos básicos en las haciendas municipales, la reestructuración del mercado agrario en el Seiscientos remodeló en parte su estructura y gestión. El fuerte endeudamiento municipal forzó a adoptar nuevos ingresos e incrementar los rendimientos de los existentes. La negociación entre concejo y censalistas o entre elite municipal, grupos privilegiados y sectores del común para definir cargas destinadas a cancelar censales se saldó con la adopción de tributaciones indirectas en las ciudades y directas en núcleos modestos, de mayor tradición comunal. Con especial vigor en las ciudades, la insuficiencia de estos ingresos impuso aumentar los impuestos sobre los principales abastos por su amplia tradición en el reino y facilidad de recaudación en detrimento de la capacidad adquisitiva de los vecinos. En este proceso, las elites urbanas demostraron una mejor adaptación de las contribuciones sobre los productos agrarios a su comercialización dentro y fuera de Aragón conforme se afianzó la reestructuración de la economía en la segunda mitad de la centuria. Artículos con una mayor proyección comercial exterior carne, trigo- desde mediados de siglo vieron sancionada la fuerte presión fiscal ya aplicada con anterioridad. Menos integrados en los propios municipales, los cánones más modestos sobre el vino y aceite parecen también ligados a estrategias de defensa de la producción local tras caer la demanda interna y crecer la competencia del mercado regional. Frente a los intereses de las elites municipales, la oposición de los grupos privilegiados y sectores humildes a estos impuestos modificó según su grado de éxito el control público del mercado, la evolución de la presión fiscal y la capacidad de consumo de la población. 


\section{APENDICE.}

CuAdro 4. PReCios del trigo en ARAgON —EN SUELdos POR CAHIZ-

\begin{tabular}{|c|c|c|c|c|c|c|c|c|c|}
\hline Año & Daroca & Barbastro & Fraga & Zaragoza & Año & Daroca & Barbastro & Fraga & Zaragoza \\
\hline 1500 & 27,20 & & & & 1551 & 50,32 & & & 47,32 \\
\hline 1501 & & & & & 1552 & 53,69 & & & \\
\hline 1502 & 26,46 & & & & 1553 & 60,78 & & & \\
\hline 1503 & & & & & 1554 & 43,00 & & & \\
\hline 1504 & 48,29 & & & & 1555 & 50,85 & & & 52,75 \\
\hline 1505 & 44,37 & & & & 1556 & & & & 54,11 \\
\hline 1506 & 25,21 & & & & 1557 & 63,92 & & & 80,30 \\
\hline 1507 & & & & & 1558 & 61,35 & & & \\
\hline 1508 & 32,75 & & & & 1559 & & & & 52,62 \\
\hline 1509 & & & & & 1560 & 46,50 & & & 37,63 \\
\hline 1510 & & & & & 1561 & 49,95 & & & 60,31 \\
\hline 1511 & 27,20 & & & & 1562 & 42,72 & & & 44,90 \\
\hline 1512 & & & & & 1563 & 44,92 & & & 48,03 \\
\hline 1513 & & & & & 1564 & 40,00 & & & 41,51 \\
\hline 1514 & 41,07 & & & 41,93 & 1565 & 41,00 & & & 39,57 \\
\hline 1515 & & & & 30,74 & 1566 & 49,39 & & & 72,50 \\
\hline 1516 & & & & & 1567 & & & & 74,16 \\
\hline 1517 & 27,40 & & & & 1568 & 52,50 & & & 48,97 \\
\hline 1518 & 26,73 & & & & 1569 & 42,44 & & & 45,19 \\
\hline 1519 & 28,94 & & & & 1570 & & 81,35 & & \\
\hline 1520 & & & & & 1571 & 78,85 & 96,70 & & \\
\hline 1521 & 30,85 & & & & 1572 & 69,60 & 26,56 & & \\
\hline 1522 & 34,75 & & & & 1573 & 68,82 & 89,40 & & \\
\hline 1523 & 25,35 & & & 35,74 & 1574 & 61,42 & 55,00 & & 65,74 \\
\hline 1524 & 39,91 & & & 33,75 & 1575 & 60,00 & 62,00 & & 66,40 \\
\hline 1525 & 25,10 & & & 28,25 & 1576 & 72,57 & 98,00 & & 74,46 \\
\hline 1526 & 54,95 & & & & 1577 & 102,78 & 119,36 & & 107,08 \\
\hline 1527 & 42,94 & 32,00 & & 37,63 & 1578 & 104,75 & 105,76 & & 119,10 \\
\hline 1528 & 38,20 & 31,33 & & 33,17 & 1579 & 144,49 & 44,25 & & \\
\hline 1529 & & 66,50 & & & 1580 & 56,25 & 44,25 & & 77,57 \\
\hline 1530 & & 66,33 & & & 1581 & 42,72 & 52,13 & & \\
\hline 1531 & & 51,50 & & & 1582 & 40,91 & 74,60 & & \\
\hline 1532 & & 30,00 & & & 1583 & & 122,73 & & \\
\hline 1533 & & 41,00 & & & 1584 & 125,00 & 136,93 & & 104,50 \\
\hline 1534 & 23,78 & 32,00 & & 41,92 & 1585 & 102,52 & 76,94 & & \\
\hline 1535 & & & & & 1586 & 70,97 & 60,17 & & \\
\hline 1536 & & & & & 1587 & 48,92 & 60,67 & & 72,22 \\
\hline 1537 & & & & 29,13 & 1588 & & 90,92 & & 71,19 \\
\hline 1538 & & & & 26,96 & 1589 & 72,00 & 90,00 & & \\
\hline 1539 & & & & & 1590 & 74,07 & 60,46 & & \\
\hline 1540 & & & & 55,75 & 1591 & 73,28 & 92,22 & & \\
\hline 1541 & & & & 60,90 & 1592 & 89,65 & 105,88 & & \\
\hline 1542 & 43,14 & & & & 1593 & 75,16 & 139,00 & & \\
\hline 1543 & & & & & 1594 & 112,53 & & & \\
\hline 1544 & 30,96 & & & & 1595 & 66,46 & 79,82 & & \\
\hline 1545 & 36,80 & & & & 1596 & 65,83 & 54,97 & & \\
\hline 1546 & & & & & 1597 & 73,45 & & & \\
\hline 1547 & & & & & 1598 & & 84,42 & & \\
\hline 1548 & 50,63 & & & & 1599 & 94,41 & 93,61 & & \\
\hline 1549 & 52,33 & & & 54,64 & 1600 & 95,11 & 99,46 & & \\
\hline 1550 & 51,25 & & & 49,04 & 1601 & 92,86 & 58,70 & & \\
\hline
\end{tabular}




\begin{tabular}{|c|c|c|c|c|c|c|c|c|c|}
\hline Año & Daroca & Barbastro & Fraga & Zaragoza & Año & Daroca & Barbastro & Fraga & Zaragoza \\
\hline 1602 & & 64,00 & & & 1655 & 72,09 & 160,00 & & 89,92 \\
\hline 1603 & 84,25 & 60,00 & & & 1656 & 74,26 & 160,00 & & 83,53 \\
\hline 1604 & 67,96 & 80,21 & 80,00 & & 1657 & 54,44 & 103,16 & & \\
\hline 1605 & 97,00 & 113,21 & & 109,45 & 1658 & 60,78 & 80,00 & & 49,15 \\
\hline 1606 & 118,00 & 118,74 & 155,33 & 125,00 & 1659 & & 85,58 & & 51,75 \\
\hline 1607 & 117,67 & & 137,33 & 130,50 & 1660 & 76,72 & 126,00 & 113,33 & 80,00 \\
\hline 1608 & 95,00 & & & 118,44 & 1661 & 82,00 & 147,66 & & 88,00 \\
\hline 1609 & 78,85 & & & 99,70 & 1662 & 65,58 & 128,00 & 74,66 & 81,45 \\
\hline 1610 & & & & & 1663 & 65,00 & 104,25 & & 74,00 \\
\hline 1611 & & & & & 1664 & 85,83 & & & 95,00 \\
\hline 1612 & 64,96 & & & & 1665 & 80,50 & 120,00 & 65,33 & 109,40 \\
\hline 1613 & 71,62 & & 112,00 & 111,34 & 1666 & & & & \\
\hline 1614 & & & 122,66 & 140,50 & 1667 & 69,47 & 99,66 & & \\
\hline 1615 & 132,56 & & & 138,50 & 1668 & 77,05 & 126,16 & & 86,77 \\
\hline 1616 & & & & 90,55 & 1669 & 73,00 & 130,00 & 80,00 & 84,65 \\
\hline 1617 & 69,00 & & & 84,75 & 1670 & 62,13 & 125,08 & 80,00 & \\
\hline 1618 & 75,30 & & & 77,32 & 1671 & 51,28 & 103,66 & 64,00 & \\
\hline 1619 & & & 86,00 & & 1672 & 52,90 & 84,25 & 48,00 & 48,97 \\
\hline 1620 & 73,45 & & 94,00 & & 1673 & 45,76 & 80,00 & 36,00 & 45,62 \\
\hline 1621 & & & & & 1674 & & 80,00 & 48,00 & 55,08 \\
\hline 1622 & 73,43 & & 96,00 & 95,28 & 1675 & 46,96 & 80,00 & 48,00 & 61,26 \\
\hline 1623 & 75,37 & & 83,33 & 85,83 & 1676 & 51,75 & 81,16 & 64,66 & 54,38 \\
\hline 1624 & & & & 74,48 & 1677 & 68,50 & 110,94 & 75,50 & 72,65 \\
\hline 1625 & 54,95 & & & 62,20 & 1678 & 63,68 & 121,33 & 90,00 & 83,08 \\
\hline 1626 & & & & 58,42 & 1679 & 63,68 & 108,50 & 56,00 & 68,50 \\
\hline 1627 & 64,20 & & 78,66 & 57,02 & 1680 & 68,82 & 109,58 & & 67,00 \\
\hline 1628 & 74,72 & & 92,66 & 84,88 & 1681 & 68,73 & 94,25 & 48,00 & 69,76 \\
\hline 1629 & & & 116,66 & 82,36 & 1682 & 55,55 & 88,88 & 56,66 & 67,52 \\
\hline 1630 & 103,28 & & 150,66 & 174,25 & 1683 & 70,25 & & 94,00 & 80,30 \\
\hline 1631 & 133,00 & 216,41 & 137,33 & 159,00 & 1684 & 84,95 & & 68,00 & \\
\hline 1632 & 96,75 & 140,00 & 114,66 & 110,50 & 1685 & 63,49 & & 77,33 & \\
\hline 1633 & 64,20 & 123,75 & 78,66 & 105,25 & 1686 & 68,01 & & 64,00 & \\
\hline 1634 & 69,83 & 110,00 & 59,33 & 80,30 & 1687 & 59,00 & 126,75 & 83,11 & \\
\hline 1635 & 75,30 & 110,00 & 67,33 & 71,65 & 1688 & 61,92 & & 56,00 & 75,83 \\
\hline 1636 & 67,07 & 114,12 & 73,66 & 74,13 & 1689 & 61,92 & 110,00 & 74,00 & 61,83 \\
\hline 1637 & 79,44 & 120,00 & 80,00 & 90,55 & 1690 & 53,00 & 84,33 & 56,00 & 48,03 \\
\hline 1638 & 101,20 & 111,41 & 84,33 & 87,85 & 1691 & 54,87 & & & 73,54 \\
\hline 1639 & 64,20 & 132,50 & 100,00 & & 1692 & 54,02 & & 64,00 & 65,33 \\
\hline 1640 & 82,70 & 140,00 & 109,33 & 69,09 & 1693 & 56,11 & & 69,33 & 59,79 \\
\hline 1641 & 71,35 & 150,00 & & & 1694 & 61,92 & & 66,67 & 64,00 \\
\hline 1642 & 42,72 & 153,25 & & 143,21 & 1695 & 60,81 & & 44,00 & 56,25 \\
\hline 1643 & 71,50 & 182,25 & & 134,97 & 1696 & 58,75 & & 40,00 & 42,92 \\
\hline 1644 & 116,50 & 236,66 & & 156,92 & 1697 & 59,90 & & 59,11 & 45,38 \\
\hline 1645 & 132,25 & 240,00 & & 143,28 & 1698 & 64,10 & & 80,00 & \\
\hline 1646 & 138,50 & & & 123,99 & 1699 & 81,50 & & 66,66 & 90,55 \\
\hline 1647 & 104,33 & 220,00 & & & 1700 & 67,16 & & 76,44 & 75,25 \\
\hline 1648 & 90,14 & 170,00 & & & 1701 & 67,18 & & 80,00 & 87,17 \\
\hline 1649 & 80,00 & 156,00 & & 71,65 & 1702 & 64,75 & & 84,00 & 75,17 \\
\hline 1650 & 79,58 & 128,00 & & 89,75 & 1703 & & & & 84,08 \\
\hline 1651 & 113,00 & 188,58 & 149,67 & 153,9 & 1704 & 68,59 & & & 75,00 \\
\hline 1652 & 107,00 & 185,33 & & 130,95 & 1705 & 62,34 & & & 76,75 \\
\hline 1653 & 65,11 & 160,00 & & 93,28 & 1706 & & & & 61,58 \\
\hline 1654 & 62,59 & 160,00 & 90,00 & 83,40 & 1707 & 61,05 & & & \\
\hline
\end{tabular}


CuAdro 5. Precios del aCeITE EN ARAgON —EN SUELDOS POR ARROBA-

\begin{tabular}{|c|c|c|c|c|c|c|c|c|}
\hline Año & Daroca & Zaragoza & Año & Daroca & Zaragoza & Año & Daroca & Zaragoza \\
\hline 1572 & 45,00 & & 1618 & 32,50 & & 1664 & & 34,00 \\
\hline 1573 & & & 1619 & 30,00 & & 1665 & & 34,00 \\
\hline 1574 & & & 1620 & 30,00 & & 1666 & & \\
\hline 1575 & & & 1621 & 30,00 & & 1667 & & \\
\hline 1576 & 31,00 & & 1622 & 27,00 & & 1668 & & 40,00 \\
\hline 1577 & 30,90 & & 1623 & 39,00 & & 1669 & & 40,00 \\
\hline 1578 & 30,00 & & 1624 & 54,00 & & 1670 & & 40,00 \\
\hline 1579 & 34,50 & & 1625 & 43,50 & & 1671 & & \\
\hline 1580 & & & 1626 & 30,00 & & 1672 & 24,00 & \\
\hline 1581 & & & 1627 & 33,90 & 26,00 & 1673 & 24,00 & 24,00 \\
\hline 1582 & & & 1628 & 39,00 & & 1674 & & \\
\hline 1583 & & & 1629 & 34,50 & & 1675 & 25,50 & 24,50 \\
\hline 1584 & & & 1630 & 40,50 & & 1676 & 21,00 & 26,50 \\
\hline 1585 & 24,00 & & 1631 & 31,50 & & 1677 & 28,50 & 31,50 \\
\hline 1586 & & 24,00 & 1632 & 45,00 & & 1678 & 27,75 & 26,50 \\
\hline 1587 & & & 1633 & 42,00 & & 1679 & 27,00 & 27,75 \\
\hline 1588 & & & 1634 & 34,50 & & 1680 & 40,50 & 24,50 \\
\hline 1589 & & & 1635 & & & 1681 & 45,00 & 37,00 \\
\hline 1590 & 42,00 & 42,00 & 1636 & & & 1682 & 32,25 & \\
\hline 1591 & 36,00 & 25,00 & 1637 & 30,90 & & 1683 & 27,00 & \\
\hline 1592 & 26,10 & & 1638 & 28,50 & & 1684 & 30,00 & \\
\hline 1593 & & & 1639 & 28,50 & & 1685 & 27,00 & \\
\hline 1594 & & & 1640 & 34,50 & & 1686 & 22,50 & 23,50 \\
\hline 1595 & 33,00 & & 1641 & & & 1687 & 22,50 & 23,00 \\
\hline 1596 & & & 1642 & & & 1688 & 24,00 & 22,25 \\
\hline 1597 & 33,90 & & 1643 & 34,50 & & 1689 & 27,00 & 23,33 \\
\hline 1598 & 33,00 & & 1644 & & 36,00 & 1690 & 24,00 & 26,00 \\
\hline 1599 & 31,50 & & 1645 & & & 1691 & 27,00 & \\
\hline 1600 & 33,00 & & 1646 & 60,00 & & 1692 & 27,00 & 27,00 \\
\hline 1601 & 39,00 & 36,00 & 1647 & 54,00 & & 1693 & 28,50 & 29,00 \\
\hline 1602 & 43,20 & 41,25 & 1648 & 49,50 & & 1694 & 30,00 & 31,00 \\
\hline 1603 & 42,00 & 47,25 & 1649 & 54,00 & & 1695 & 36,00 & 32,50 \\
\hline 1604 & & & 1650 & 41,10 & 42,00 & 1696 & 27,00 & 30,00 \\
\hline 1605 & 33,00 & 38,00 & 1651 & 45,00 & 48,00 & 1697 & 27,00 & \\
\hline 1606 & 33,00 & 38,00 & 1652 & 54,00 & 55,00 & 1698 & & 40,00 \\
\hline 1607 & & & 1653 & 52,50 & 55,00 & 1699 & 42,00 & \\
\hline 1608 & 30,50 & & 1654 & 36,00 & 37,75 & 1700 & 48,00 & 33,33 \\
\hline 1609 & 30,50 & & 1655 & 34,20 & & 1701 & 36,00 & 38,00 \\
\hline 1610 & 28,50 & & 1656 & 31,50 & & 1702 & 36,00 & 33,50 \\
\hline 1611 & 33,00 & & 1657 & 34,50 & & 1703 & & 32,66 \\
\hline 1612 & 33,00 & & 1658 & 30,00 & & 1704 & & 28,33 \\
\hline 1613 & 33,00 & & 1659 & 32,25 & & 1705 & & 25,00 \\
\hline 1614 & 30,00 & & 1660 & 33,00 & 34,00 & 1706 & & 29,66 \\
\hline 1615 & 34,50 & & 1661 & & 34,00 & 1707 & & 22,00 \\
\hline 1616 & 27,00 & & 1662 & 36,00 & & 1708 & & 27,00 \\
\hline 1617 & 31,50 & 32,00 & 1663 & 28,50 & & & & \\
\hline
\end{tabular}


CUADRO 6. PRECIOS DEL CORDERO EN TRES CARNICERIAS DE ARAGON —EN DINEROS POR LIBRA-

\begin{tabular}{|c|c|c|c|c|c|c|c|}
\hline Año & Daroca & Zaragoza & Barbastro & Año & Daroca & Zaragoza & Barbastro \\
\hline 1523 & 12,00 & & & 1573 & & & \\
\hline 1524 & 12,00 & & & 1574 & & & \\
\hline 1525 & 12,00 & & & 1575 & & 35,00 & \\
\hline 1526 & & & & 1576 & 32,00 & 34,30 & \\
\hline 1527 & & & & 1577 & & 34,00 & \\
\hline 1528 & & & & 1578 & & 30,60 & \\
\hline 1529 & & & & 1579 & 28,00 & 29,00 & \\
\hline 1530 & & & & 1580 & & & \\
\hline 1531 & & & & 1581 & & & \\
\hline 1532 & & & & 1582 & & & \\
\hline 1533 & & & & 1583 & 28,00 & & \\
\hline 1534 & & & & 1584 & & & \\
\hline 1535 & & & & 1585 & 32,00 & & \\
\hline 1536 & & & & 1586 & & & \\
\hline 1537 & & & & 1587 & 35,00 & & 34,00 \\
\hline 1538 & & & & 1588 & 32,00 & & \\
\hline 1539 & & & & 1589 & & 42,00 & 38,00 \\
\hline 1540 & & & & 1590 & 40,00 & 42,00 & \\
\hline 1541 & & & & 1591 & 36,00 & 42,00 & \\
\hline 1542 & & 14,00 & & 1592 & 32,00 & & \\
\hline 1543 & & 14,00 & & 1593 & & & \\
\hline 1544 & & 14,50 & & 1594 & & 34,00 & \\
\hline 1545 & & 15,00 & & 1595 & & 34,00 & \\
\hline 1546 & & 15,00 & & 1596 & 32,00 & & \\
\hline 1547 & & 15,00 & & 1597 & 33,00 & & \\
\hline 1548 & & 15,00 & & 1598 & 32,00 & & \\
\hline 1549 & & 16,00 & & 1599 & & & \\
\hline 1550 & & 16,00 & & 1600 & & & \\
\hline 1551 & & 16,00 & & 1601 & 52,00 & 48,00 & 44,00 \\
\hline 1552 & 22,00 & 16,00 & & 1602 & 48,00 & 46,60 & 40,00 \\
\hline 1553 & & 16,00 & & 1603 & & 50,00 & 44,00 \\
\hline 1554 & 21,00 & & & 1604 & & 52,00 & \\
\hline 1555 & 20,00 & & & 1605 & 36,00 & 42,00 & \\
\hline 1556 & 20,00 & 18,00 & & 1606 & 36,00 & 42,00 & \\
\hline 1557 & & 18,00 & & 1607 & 36,00 & & \\
\hline 1558 & 20,00 & & & 1608 & & & \\
\hline 1559 & & & & 1609 & 31,00 & & \\
\hline 1560 & & & 30,00 & 1610 & 34,00 & 36,00 & \\
\hline 1561 & 27,00 & & & 1611 & & 36,00 & \\
\hline 1562 & & & & 1612 & 42,00 & & 42,00 \\
\hline 1563 & & & & 1613 & & & \\
\hline 1564 & & & & 1614 & & 48,00 & 38,00 \\
\hline 1565 & & & & 1615 & & 48,00 & \\
\hline 1566 & & & & 1616 & & 42,00 & \\
\hline 1567 & 31,00 & 27,00 & & 1617 & 40,00 & 42,00 & 36,00 \\
\hline 1568 & & 27,00 & & 1618 & 40,00 & & 42,00 \\
\hline 1569 & 31,00 & & & 1619 & 37,00 & & \\
\hline 1570 & 30,00 & & & 1620 & & & \\
\hline 1571 & & & & 1621 & 40,00 & & \\
\hline 1572 & & & & 1622 & 36,00 & & \\
\hline
\end{tabular}




\begin{tabular}{|c|c|c|c|c|c|c|c|}
\hline Año & Daroca & Zaragoza & Barbastro & Año & Daroca & Zaragoza & Barbastro \\
\hline 1623 & & 42,00 & & 1663 & 48,00 & 48,00 & \\
\hline 1624 & & 42,00 & & 1664 & 48,00 & & \\
\hline 1625 & & & & 1665 & 44,00 & & \\
\hline 1626 & & & & 1666 & 44,00 & & 40,00 \\
\hline 1627 & & & 42,00 & 1667 & 44,00 & & 40,00 \\
\hline 1628 & 44,00 & & 40,00 & 1668 & 42,00 & & 40,00 \\
\hline 1629 & & & & 1669 & & & 40,00 \\
\hline 1630 & & & & 1670 & 48,00 & & 40,00 \\
\hline 1631 & 45,00 & & & 1671 & 47,00 & & 40,00 \\
\hline 1632 & & & & 1672 & 46,00 & & 40,00 \\
\hline 1633 & & & & 1673 & 46,00 & & 40,00 \\
\hline 1634 & & & & 1674 & 36,00 & & 40,00 \\
\hline 1635 & & & & 1675 & 36,00 & & 40,00 \\
\hline 1636 & 45,00 & & & 1676 & & & 40,00 \\
\hline 1637 & 44,00 & & & 1677 & & & 37,30 \\
\hline 1638 & 43,00 & & & 1678 & 37,00 & & 36,00 \\
\hline 1639 & 44,00 & 48,00 & & 1679 & 36,00 & 44,00 & 36,00 \\
\hline 1640 & & 48,00 & & 1680 & 36,00 & 44,00 & 36,00 \\
\hline 1641 & 47,00 & & & 1681 & 45,00 & 44,00 & 39,00 \\
\hline 1642 & & 53,00 & & 1682 & & 44,00 & \\
\hline 1643 & 46,00 & 53,50 & & 1683 & & 44,00 & \\
\hline 1644 & & 54,00 & & 1684 & & 44,00 & \\
\hline 1645 & & & & 1685 & & 44,00 & \\
\hline 1646 & & & 54,00 & 1686 & & 44,00 & \\
\hline 1647 & 47,00 & & & 1687 & & 44,00 & 40,00 \\
\hline 1648 & 47,00 & & & 1688 & & 44,00 & 40,00 \\
\hline 1649 & 49,00 & & & 1689 & & 44,00 & \\
\hline 1650 & & 60,00 & & 1690 & & 44,00 & \\
\hline 1651 & 52,00 & 50,60 & & 1691 & & 44,00 & \\
\hline 1652 & & 46,00 & & 1692 & & 44,00 & \\
\hline 1653 & & 46,00 & & 1693 & & 44,00 & \\
\hline 1654 & & 50,00 & & 1694 & & 44,00 & \\
\hline 1655 & & 52,00 & & 1695 & 51,00 & 53,00 & 45,00 \\
\hline 1656 & & 52,00 & & 1696 & 42,00 & 48,00 & \\
\hline 1657 & & 52,00 & & 1697 & & 48,00 & \\
\hline 1658 & & 52,00 & 48,00 & 1698 & & 48,00 & \\
\hline 1659 & 48,00 & 49,30 & 38,00 & 1699 & & 48,00 & \\
\hline 1660 & 48,00 & 48,00 & & 1700 & 42,00 & & \\
\hline 1661 & 48,00 & 48,00 & & 1701 & 42,00 & & \\
\hline 1662 & 48,00 & 48,00 & & 1702 & 42,00 & & \\
\hline
\end{tabular}

